\title{
Ectopic expression of the TERE1 (UBIAD1) protein inhibits growth of renal clear cell carcinoma cells: Altered metabolic phenotype associated with reactive oxygen species, nitric oxide and SXR target genes involved in cholesterol and lipid metabolism
}

\author{
WILLIAM J. FREDERICKS ${ }^{1}$, HANKUN YIN ${ }^{1,2}$, PRITI LAL ${ }^{3}$, RAGHUNATH PUTHIYAVEETTIL ${ }^{3}$, \\ STEPHEN B. MALKOWICZ ${ }^{1}$, NATHANIEL J. FREDERICKS ${ }^{1}$, JOHN TOMASZEWSKI ${ }^{4}$, \\ FRANK J. RAUSCHER III ${ }^{5}$ and S. BRUCE MALKOWICZ ${ }^{1}$
}

\begin{abstract}
${ }^{1}$ Division of Urology, Department of Surgery, University of Pennsylvania and Veterans Affairs Medical Center Philadelphia, Philadelphia, PA 19104, USA; ${ }^{2}$ Department of Urology of Zhongshan Hospital, Fudan University, Shanghai 200016, P.R. China; ${ }^{3}$ Department of Pathology and Laboratory Medicine, University of Pennsylvania Medical Center, Philadelphia, PA 19104; ${ }^{4}$ Pathology and Anatomical Sciences, Buffalo, NY 14214;

${ }^{5}$ The Wistar Institute, Philadelphia, PA 19104, USA
\end{abstract}

Received May 3, 2013; Accepted May 21, 2013

DOI: 10.3892/ijo.2013.1985

\begin{abstract}
Current studies of the TERE1 (UBIAD1) protein emphasize its multifactorial influence on the cell, in part due to its broad sub-cellular distribution to mitochondria, endoplasmic reticulum and golgi. However, the profound effects of TERE1 relate to its prenyltransferase activity for synthesis of the bioactive quinones menaquinone and COQ10. Menaquinone (aka, vitamin K-2) serves multiple roles: as a carrier in mitochondrial electron transport, as a ligand for SXR nuclear hormone receptor activation, as a redox modulator, and as an alkylator of cellular targets. We initially described the TERE1 (UBIAD1) protein as a tumor suppressor based upon reduced expression in urological cancer specimens and the inhibition of growth of tumor cell lines/xenografts upon ectopic expression. To extend this potential tumor suppressor role for the TERE1 protein to renal cell carcinoma (RCC), we applied TERE1 immunohistochemistry to a TMA panel of 28 RCC lesions and determined that in $57 \%$ of RCC lesions, TERE1 expression was reduced (36\%) or absent (21\%). Ectopic TERE1 expression caused an $80 \%$ decrease in growth of Caki-1 and Caki-2 cell lines, a significantly decreased colony formation, and increased caspase 3/7 activity in a panel of RCC cell lines. Furthermore, TERE1 expression increased mitochondrial oxygen consumption and hydrogen production, oxidative stress and NO production. Based on the elevated
\end{abstract}

Correspondence to: Dr William J. Fredericks, Division of Urology, Department of Surgery, University of Pennsylvania and Veterans Affairs Medical Center Philadelphia, University and Woodland Ave., Research Building, Room A418, Philadelphia, PA 19104, USA E-mail: wjfredericks@verizon.net

Key words: TERE1, UBIAD1, TBL2, renal clear cell carcinoma, mitochondria, vitamin K-2, SXR target genes, lipid metabolism cholesterol and altered metabolic phenotype of RCC, we also examined the effects of TERE1 and the interacting protein TBL2 on cellular cholesterol. Ectopic TERE1 or TBL2 expression in Caki-1, Caki-2 and HEK 293 cells reduced cholesterol by up to $40 \%$. RT-PCR analysis determined that TERE1 activated several SXR targets known to regulate lipid metabolism, consistent with predictions based on its role in menaquinone synthesis. Loss of TERE1 may contribute to the altered lipid metabolic phenotype associated with progression in RCC via an uncoupling of ROS/RNS and SXR signaling from apoptosis by elevation of cholesterol.

\section{Introduction}

Kidney cancer is the third most common genitourinary cancer with 64,770 new cases per year in the US in $2012(1,2)$. The majority $(75 \%)$ are renal clear cell carcinomas (RCC), which have the highest mortality to incidence ratios or all urologic malignancies resulting in 13,570 deaths per year due to their extreme insensitivity to chemo- and radiation therapy. The incidence is twice as high in men than women and associated with risk factors such as: advanced age, tobacco use, and obesity $(3,4)$. In the majority of RCC, the HIF1 complex is constitutively activated due to mutation of the Von Hippel-Lindau tumor suppressor (VHL), gene and inactivation of the prolyl hydroxylation that targets the HIFs to be degraded $(5,6)$. As a result of HIF1 stabilization, there is an induction of a hypoxic gene expression program (GLUT1, VEGF, iNOS, EPO) that support proteins involved in angiogenesis and oxygenation $(5,7,8)$. This had led to therapies targeting angiogenesis which have achieved only partial responses $(9,10)$, and the necessity for further research into new factors involved in RCC progression. A role for elevated tumor cell cholesterol and altered lipid metabolism has been implicated in the etiology and disease progression in renal clear cell cancer based on its potential for apoptotic 
interference (4,11-16). Currently favored theories propose that RCC consists of a group of diseases of abnormal metabolism relating to oxygen, iron, energy and nutrient sensing pathways $(8,17,18)$. The concept of an aberrant metabolic phenotype of RCC has been further supported by several studies elaborating mechanisms of defects in mitochondrial metabolism in the TCA cycle that lead to metabolic imbalance and HIF1 stabilization (19-22). Our current study of the role of TERE1 in RCC is based on its role in synthesis of menaquinone (23) that exerts profound influence on mitochondrial function, oxidative and nitrosative stress, and regulation of lipid metabolism via activation of SXR nuclear receptor signaling, and several other mechanisms that lead to growth inhibition and increased apoptosis (24).

We originally reported the cloning of the TERE1 gene (aka UBIAD1) and showed conserved mRNA expression in urothelium and other normal tissues; however, reduced mRNA levels were found in muscle-invasive transitional cell carcinoma (TCC) of the bladder and metastatic prostate cancer $(25,26)$. Our immunohistochemical analysis determined TERE1 protein expression was decreased in a third of invasive TCC (25-27). Ectopic TERE1 expression in bladder cancer and prostate cancer cell lines resulted in dramatic inhibition of in vitro growth and tumorigenicity (25-27). Protein interaction studies identified APOE, TBL2, HMGR, and SOAT-1 as TERE1-interacting proteins, strongly implicating a role in cholesterol homeostasis (28). TERE1 gene mutations were discovered to cause a rare disease of elevated corneal cholesterol and lipid deposition called Schnyder's corneal dystrophy (SCD) $(29,30)$, and affect interactions with APOE, HMGR, and with TBL2 $(24,27,31)$.

A unifying hypothesis towards understanding effects on lipid metabolism emerged when TERE1 was identified as the prenyltransferase required for vitamin K-2 biosynthesis: conversion of vitamin K-1 (phylloquinone), to K-2 (menaquinone) with K-3 (menadione) as an intermediate (23). Vitamin K-2 is a potent activator of the SXR nuclear hormone receptor that has established roles in regulation of lipid metabolism and cholesterol efflux $(32,33)$. Quinone metabolism also provides a basis for understanding effects on redox balance and mitochondrial function. There is abundant literature describing the activity of exogenous vitamin K-2 and K-3 in the inhibition of tumor cell growth based on the redox-cycling and alkylating properties of quinones (34-36), which strongly suggests this may be a mechanism of TERE1 tumor suppressor activity. A further dimension of TERE1 activity is based on the established role of menaquinone as an electron carrier in the electron transport chain, ETC, of anaerobic bacteria and anaerobic mitochondria $(37,38)$. This function was supported by studies of the Drosophila homolog of TERE1/UBIAD1, heix, that demonstrated a role in vitamin K-2-mediated mitochondrial electron transport and ATP production (39). We recently conducted an immunoelectronmicroscopic analysis demonstrating that TERE1 can co-localize with TBL2 in mitochondria, and increase the mitochondrial transmembrane potential, and generate ROS/RNS (24).

Given the altered metabolic phenotype of RCC and the emerging view of a metabolic mode of tumor suppression attributed to TERE1, we have conducted a preliminary investigation of TERE1 in RCC. The principle objectives of this study were to establish a TERE1-negative expression phenotype in a over half of the lesions from a tumor microarray (TMA) set of human RCC tumor specimens, demonstrate that ectopic TERE1 expression resulted in an $80 \%$ decrease in growth of Caki-1 and Caki-2 cells and suppression of colony forming ability in a panel of RCC cell lines, as well as an increase in caspase 3/7 activity. We show TERE1 can activate mitochondrial activity using extracellular flux analysis and lead to elevations in ROS/ RNS. TERE1 and TBL2 reduced Caki-1 and Caki- 2 cell cholesterol by up to $40 \%$ and activated a common set of SXR target genes with roles in cholesterol and lipid metabolism. We discuss the hypothesis that compromise of TERE1 by reduced expression in RCC, may represent a loss of stress, redox and SXR signaling that affects lipid metabolism and growth.

\section{Materials and methods}

Immunohistochemistry. Five-micron sections from formalinfixed paraffin-embedded tissue specimens were deparaffinized in xylene and rehydrated in graded alcohol with quenching of endogenous peroxidase activity by treatment with $2 \%$ $\mathrm{H}_{2} \mathrm{O}_{2}$ in methanol. The slides were blocked in $10 \%$ normal rabbit serum and incubated with affinity-purified anti-TERE1 $(2 \mu \mathrm{g} / \mathrm{ml})$ for $14 \mathrm{~h}$ at $4^{\circ} \mathrm{C}$. After washes, the slides were incubated with biotin-conjugated rabbit IgG for $30 \mathrm{~min}$ followed by streptavidin-conjugated peroxidase and 3'3-diaminobenzidine, and counterstained with hematoxylin.

Cell lines and antibodies. The human RCC cell lines were obtained from the American Type Culture Collection (Manassas, VA) and grown according to supplier's instructions. Caki-1 (HTB-46) and Caki-2 (HTB-47) cells are derived from clear cell carcinoma of kidney. The ACHN (CRL-1611), 786-O (CRL-1932), A704 (CRL-7911), and A-498 (HTB-44) are all derived from human renal cell adenocarcinomas. Goat antiTERE1 antibodies (Santa Cruz) and rabbit anti-TBL2 (216-309) (Sigma) were previously characterized $(24,27)$.

Expression vectors. All expression plasmids, adenovirus and lentivirus used for ectopic expression by transfection and transduction were derived in our laboratory and have been previously described $(24,27)$.

Nucleofection and viral transduction. Nucleofection was performed with the Nucleofector II system according to the manufacturer's protocol (Amaxa/Lonza Cologne, Germany) and has been previously described (27). Infectious adenovirus was produced and amplified in HEK293A cells following guidelines from Invitrogen and titered via an anti-hexon staining procedure from Clontech to $>4 \times 10^{8} \mathrm{IU} / \mathrm{ml}$. Infections were in the presence of $6 \mu \mathrm{g} / \mathrm{ml}$ polybrene and monitored via AdGFP expression.

Preparation of cell extracts. Cell lines that had been transfected via Amaxa nucleofection or transduced with Ad-LACZ, Ad-TERE1, or Ad-TBL2 adenovirus, were harvested 36-72 h later from $10 \mathrm{~cm}$ plates by washing in ice cold PBS with protease inhibitors, and scraping to freeze cell pellets. Whole cell extracts were prepared and analyzed by methods previously described $(24,27)$. In detail, whole cell extracts were prepared by lysis in a mixture of different detergent buffers: $0.5 \%$ of ASB-14, CHAPS, Octyl glucoside, NP-40 (Calbiochem) or 
BRIJ 96/99, Triton X-100 (Sigma), containing $150 \mathrm{mM} \mathrm{NaCl}$, $10 \mathrm{mM}$ Tris- $\mathrm{HCl}(\mathrm{pH} 7.4)$ and protease inhibitors: $1.0 \mathrm{mM}$ EDTA, $2 \mu \mathrm{g} / \mathrm{ml}$ leupeptin and pepstatin, $10 \mu \mathrm{g} / \mathrm{ml}$ aprotinin, and $1.0 \mathrm{mM}$ phenylmethylsulfonlyfluoride (PMSF), and one complete mini protease inhibitor cocktail tablet (Roche) per $10 \mathrm{ml}$ lysis buffer. After brief sonication, lysates were clarified at $16,000 \mathrm{x} \mathrm{g}$ for $30 \mathrm{~min}$ at $4^{\circ} \mathrm{C}$ and supernatants were evaluated for protein concentration by BCA assay using BSA as a standard. Equal amounts of cell lysate (50 $\mu \mathrm{g}$ of protein) were fractionated by SDS-PAGE in 4-20\% Bis-Tris gels (Invitrogen) run with MES buffer under reducing conditions and were transferred to nitrocellulose membranes. The non-specific protein binding sites on blots were blocked by incubation in $5 \%$ non-fat dry milk in TBS $[150 \mathrm{mM} \mathrm{NaCl}, 10 \mathrm{mM}$ Tris- $\mathrm{HCl}$ ( $\mathrm{pH}$ 7.4)] and then blots were probed for $2 \mathrm{~h}$ at room temperature with affinity purified primary antibodies at $\sim 0.2 \mu \mathrm{g} / \mathrm{ml}$ in TBS pH 7.4 with 3\% non-fat dry milk and $0.05 \%$ Tween-20. Horseradish peroxidase-conjugated goat anti-rabbit IgG (BioRad) was used to detect immune complexes on immunoblots. Blots were treated with Supersignal West Pico chemiluminescence reagents (Pierce) and were visualized on X-ray film (Kodak, Biomax-MR, or Thermo CL-X Posure film).

Cell proliferation, colony formation, and caspase 3/7 assays. Cell growth assays were conducted in quadruplicate wells of 96-well luminometry plates using the Cell titer-Glo Luminescent. Cell viability kit following specifications provided by Promega. Colony formation assays were initiated $48 \mathrm{~h}$ after lentivirus transduction using blasticidin selection for 3 weeks with selective media replacement every 4 days followed by staining with methylene blue or cresyl violet. For selection of resistant colonies the following Blastcidin concentrations were used: Caki-1 $(5.5 \mu \mathrm{g} / \mathrm{ml})$ and Caki-2 $(3.0 \mu \mathrm{g} / \mathrm{ml}), \operatorname{ACHN}(5.5 \mu \mathrm{g} / \mathrm{ml}), 786-\mathrm{O}$ (7 $\mu \mathrm{g} / \mathrm{ml}), \mathrm{A} 704(5 \mu \mathrm{g} / \mathrm{ml})$, and A-498 $(5 \mu \mathrm{g} / \mathrm{ml})$. Caspase 3/7 assays used the Promega Caspase-Glo luciferase assays as specified by manufacturer. Caki- 1 and Caki- 2 cells were plated in 96-well luminometry plates for cell culture and quadruplicate wells infected for $60 \mathrm{~h}$ with Ad-LACZ, Ad-TERE1, or Ad-miRNA TERE1 (27).

Extracellular flux analysis. All measurements of $\mathrm{O}_{2}$ consumption rate (OCR) and proton production, expressed as the extracellular acidification rate (ECAR), were performed with a Seahorse Bioscience XF24 extracellular flux analyzer following procedures from the manufacturer (Billirica, MA). Caki-1 cells were infected for $48 \mathrm{~h}$ with the Ad-LACZ control or Ad-TERE1 virus and then were plated at $1.5,3.0,4.5 \times 10^{4}$ cells/well onto poly-L-lysine coated Seahorse 24 -well plates $18 \mathrm{~h}$ prior to the assay. Data analysis showed $3.0 \times 10^{4}$ cells/well to be the optimal seeding density. Immediately following the addition of fresh medium, OCR and proton production, expressed as the ECAR, were quantified to obtain baseline levels of these processes. After basal measurements cyanide p-trifluoromethoxy-phenylhydrazone, FCCP, was injected into parallel wells to determine the maximum responses, and $10 \mu \mathrm{M}$ vitamin $\mathrm{K}-2$ to compare with TERE1 expression.

Oxidative and nitrosative stress assays. Oxidative stress measurements were conducted using cell imaging of dihydrorhodamine 123 and CellROX deep red fluorogenic probes
(Molecular Probes/Invitrogen). Dihydrorhodamine 123 reacts with either hydrogen peroxide (in presence of peroxidase, cytochrome c or $\mathrm{Fe}^{2+}$ ) or with peroxynitrate (formed when nitric oxide reacts with superoxide). Once dihydrorhodamine 123 is oxidized to rhodamine 123 , it localizes to mitochondria. CellROX deep red oxidation is specific for ROS but not RNS Caki-1 and Caki-2 cell lines were plated in 96-well optically clear plates (Costar 3720) and infected for 48-72 h with Ad-LACZ, or Ad-TERE1. Cellular NO/RNS production was measured using the fluorescent probe 4-amino-5-methylamino-2',7'difluorofluescein diacetate, DAF-FM-DA (Molecular Probes/ Invitrogen; D-23844); DAF-FM reacts with NO and RNS to form a fluorescent benzotriazole. Our procedures for loading cells with these fuorogenic probes and visualization by laser scanning confocal microscopy (Olympus Fluoview FV1000; $488 \mathrm{~nm}$ Ar laser excitation/525 nm emission; 10x, 0.3NA objective) have been previously detailed (24). Cells were loaded with DAF-FM by incubation in DPBS containing $5 \mu \mathrm{M}$ DAF-FM-DA and $5 \mu \mathrm{M}$ carboxy PTIO (Cayman Chemicals), a cell permeant NO scavenger to prevent DAF-FM from reacting with any RNS produced during dye loading. After 45 min loading at room temperature in the dark, cultures were washed 4 times with warm HBSS to remove unloaded DAF-FM-DA and cPTIO, followed by $\sim 10$ min to allow for loaded dye retention before imaging was performed. Care was taken to follow the loading protocol strictly to normalize dye loading between samples. Images were captured at 10 -sec intervals (scan speed $12 \mu \mathrm{sec} /$ pixel). Baseline DAF-FM fluorescence was determined by averaging the first 20 frames of each experiment. NO production was initiated by addition of modified Hank's balanced salt solution (HBSS, $\mathrm{pH}$ 7.4) containing $1 \mathrm{X}$ minimal essential medium (MEM) amino acids (Gibco) to provide a source of arginine $(\sim 0.6 \mathrm{mM})$ for $\mathrm{NO}$ production and measured for $10 \mathrm{~min}$. Menaquinone $30 \mu \mathrm{M}$ was added during imaging to assess immediate responses. Normalization of DAF-FM fluorescence changes was made after subtraction of off-cell background fluorescence.

Cholesterol assay. The cholesterol content of J82 cell lysates harvested after $72 \mathrm{~h}$ of transduction with Ad-LACZ, Ad-TERE1, Ad-TBL2, or treatment with vitamin K-1 $(30 \mu \mathrm{M})$, $\mathrm{K}-2(30 \mu \mathrm{M}), \mathrm{K}-3(10 \mu \mathrm{M})$ was detected using an Amplex Red Cholesterol Assay kit relative to a dilution series of cholesterol standards as specified (Invitrogen). Lysates were prepared as previously described (27).

RNA isolation, reverse transcription and Fluidigm RT-PCR TaqMan expression assays. Caki-1 cells were grown to $80 \%$ confluency, transduced with Ad-LACZ, Ad-TERE1, Ad-TBL2 and $\sim 5 \times 10^{6}$ cells were lysed in $2 \mathrm{ml}$ TRIzol after $72 \mathrm{~h}$. Total RNA was isolated from TRIzol cell lysates (Invitrogen, Carlsbad, CA), using the Ambion Pure-Link RNA Mini kit according to the procedures specified by the manufacturer (Catalog 12183-081A). RNA quantity was determined using a Nanodrop ND-1000 spectrophotometer (Thermo Scientific, Waltham, MA) and quality was assessed using an Agilent 2100 Bioanalyzer (Agilent Technologies, Santa Clara, CA). The cDNA synthesis, specific target pre-amplification, and Fluidigm RT-PCR TaqMan expression assays were performed using procedures recommended by ABI Biosciences and Fluidigm (40) and were performed at the UPENN Molecular Profiling Facility as previ- 


\section{TERE1}

Motifs:

SCD Mutations:

Antibodies:

A
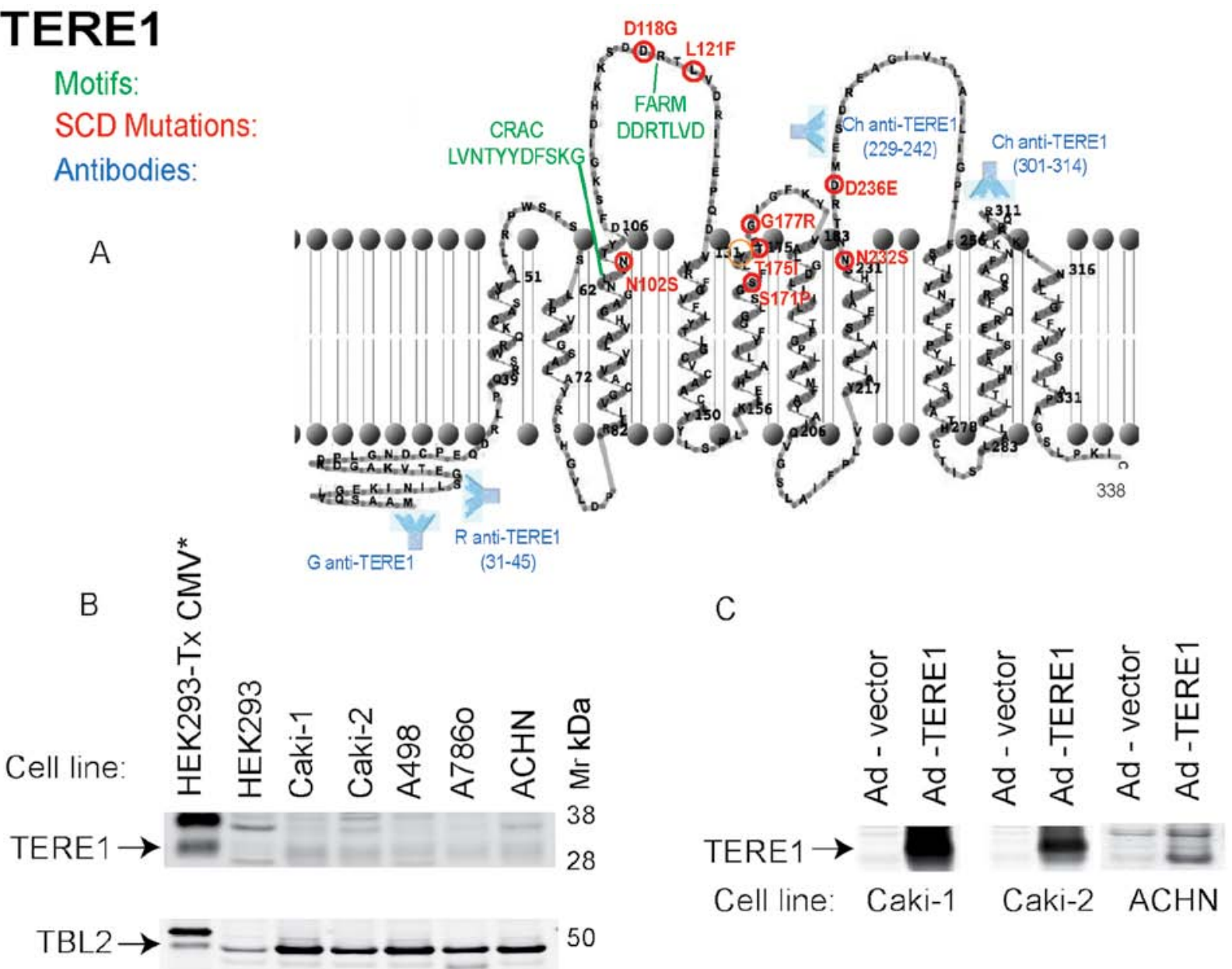

Figure 1. A, Trans-membrane model of TERE1 protein (left) depicting sites of SCD point mutations (red), conserved CRAC and FARM prenyl binding motifs, and antigen regions for polyclonal antibodies. B, Expression of endogenous TERE1 and TBL2 in human RCC cell lines from ATCC. Equal protein amounts of cell lysates from RCC cell lines indicated in labels were resolved by SDS-PAGE, immunoblotted, and probed with indicated antibodies. HEK293 transfected with Flag-TERE1 or Flag-TBL2 (depicted as HEK293-Tx CMV*) served as positive controls for antibodies. C, Ectopic expression of TERE1 in Caki-1, Caki-2, and ACHN RCC cell lines after infection with adenovirus encoding LACZ vector or TERE1 cDNA.

ously described (24). Data were analyzed using the Fluidigm BioMark Gene Expression Data Analysis software to obtain $\Delta \Delta \mathrm{Ct}$ values and expressed as a ratio to the Ad-vector control to determine the fold change in gene expression. The TaqMan probes were purchased from Applied Biosystems/Invirogen. In detail, all TaqMan gene expression assays for RT-PCR were as 5' FAM $^{\mathrm{TM}}$ reporter dye/3' MGB/nonfluorescent quencher (NFQ) from Applied Biosystems/Invitrogen. Probes were inventoried assays selected to span an exon junction and are listed: human $\beta$-actin 4333762F, GUSB 4333767F, human PPIA 4333763F, HIF1a ID: Hs00153153_m1, HMOX ID: Hs01110250_m1, TSC2 ID: Hs01020387_m1, VKOR ID: Hs01653025_m1, NQO2 ID: Hs01061270_m1, NQO1 ID: Hs01045994_m1, GAS6 ID: Hs00181323_m1, AXL ID: Hs00242357_m1, HMGCS ID: Hs00266810_m1, CD36, SCARB3 ID: Hs00169627_m1, CYP7A1 ID: Hs00167982_m1, APOE ID: Hs00171168_m1, CPT1AID:Hs00912671_m1,FBXW7Hs00217794_m1,INSIG1 made to order 255 Hs04186616_m1,CYP11A1 ID: Hs00167984_ m1, STAR ID: Hs00264912_m1, TSPO ID: Hs00559362_m1, SREBF1 ID: Hs01088691_m1, SREBF2 ID: Hs01081784_m1, FASN ID: Hs01005622_m1, SCD2 ID: Hs00227692_m1, SCD1 ID: Hs01682761_m1ST2A1 Hs00234219_m1, FDPS
TERE1

Staining: Absent or Low $57 \%$

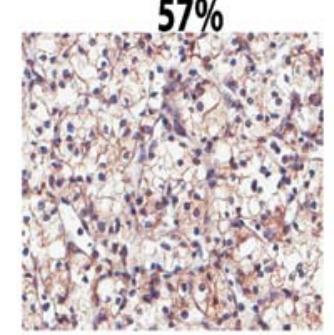

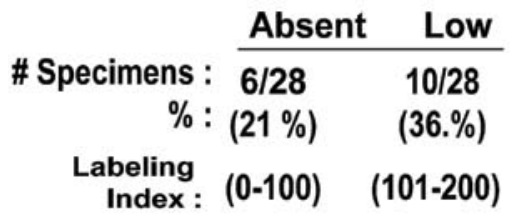

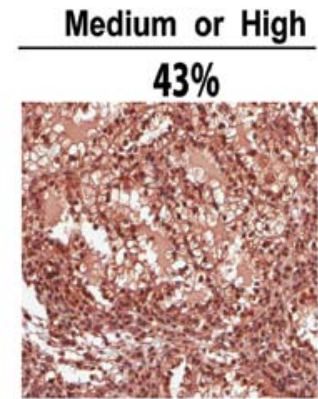

intensity of staining $(+1$ to +3$) \times \%$ of tumor cells staining

Figure 2. Reduced TERE1 staining in renal clear cell carcinoma tissue microarray: representative labeling index (LI) groups (low, mild, medium, high) based on intensity of staining $x$ percentage of tumor cells staining with antiTERE1 antibody. TERE1 protein is reduced in almost $60 \%$ of human renal clear cell cancer specimens. 
ID: Hs00266635_m1, SXR ID: Hs00243666_m1, TBL2 ID: Hs00202878_m1, UBIAD1 ID: Hs00203343_m1, ABCG1 ID: Hs00245154_m1, ABCA1 ID: Hs01059118_m1, ABCB1 ID: Hs01067802_m1, CYP3A4 ID: Hs00604506_m1, AKR1C3 ID: Hs00366267_m1, AKR1C2 ID: Hs00912742_m1, AKR1C1 ID: Hs00413886_m1, SRD5A1 ID: Hs00602694_mH, HSD3B1 ID: Hs00426435_m1, OATP1B1 ID: Hs00272374_m1, 3-hydroxy3-methylglutaryl-CoA reductase ID: Hs00168352_m1, CYP27A1 ID: Hs01026016_m1, CYP24A1 ID: Hs00167999_ m1,CYP17A1 ID: Hs01124136_m1, MRP2 ID: Hs01091188_m1, UGT2B15 ID Hs03008769_g1, UGT2B17 ID: Hs00854486_sH.

\section{Results}

Features of TERE1 (UBIAD1) and interacting proteins. TERE1 is a ten $\alpha$-helical transmembrane domain protein of 338 amino acid residues that localizes to ER, golgi and mitochondria $(23,24,41)$. As depicted in Fig. 1, the mutations (in red) associated with SCD occur in residues on one side of the membrane, either in aqueous loops or close to one bilayer surface (29). These loops may constitute a binding interface for interacting proteins, APOE, TBL2, HMGR, and SOAT-1 $(24,27,31)$. Also featured is a well-conserved CRAC motif $\left[\mathrm{L} / \mathrm{V}\left(\mathrm{X}_{1-5}\right) \mathrm{Y}\left(\mathrm{X}_{1-5}\right)\right.$ $\mathrm{R} / \mathrm{K}$ ] involved in binding cholesterol $(27,42,43)$, and an adjacent FARM motif DDXXXXD (farnesyl binding aspartate-rich motif), a putative ligand/polyprenyldiphosphate binding site (29). The presence of a heme regulatory motif and oxidoreductase motif, not shown, suggests that TERE1 activity may be affected by cellular redox state (29). The approximate polyclonal antibody binding sites used in this study are also shown. We evaluated TERE1 and TBL2 expression in a panel of RCC cell lines. Fig. 1B shows a very low level of endogenous TERE1 levels in several RCC cell lines (top) yet conserved expression of TBL2 (bottom). Reduced TERE1 expression may be a feature in common among RCC cell lines and some RCC cancer specimens. We ectopically expressed the TERE1 protein in Caki-1, Caki-2, and ACHN cells by introducing cDNAs via infection with adenoviral vectors and confirmed expression of the $\sim 37 \mathrm{kDa}$ TERE1 protein via immunoblots (Fig. 1C).

TERE1 expression in renal clear cell carcinoma. Based on a view of TERE1 as a modulator of lipid metabolism, and RCC as disease of altered metabolism, we have conducted a preliminary investigation of TERE1 in RCC. We examined TERE1 expression in a human tumor microarray (TMA) of renal clear cell carcinoma specimens via an immunohistochemical analysis using a chicken anti-TERE1 (229-242) antibody (Fig. 2). The representative anti-TERE1 staining levels were sorted into the four groups (absent, low, medium, and high) based on the assigned labeling index. The average value obtained from three cores was assigned as the score for that particular case. Overall, TERE1 staining was heterogeneous in 28 specimens. TERE1 staining was absent or low in almost $60 \%$ of RCC specimens, hence may represent a significant phenotype in renal cancer.

Ectopic TERE1 expression inhibits growth and colony formation of RCC cell lines. We evaluated the growth of Caki-1, Caki-2 and A704 renal carcinoma cell lines upon TERE1 expression to determine its potential for growth inhibition as we had observed with TERE1 in bladder and prostate cancer cells

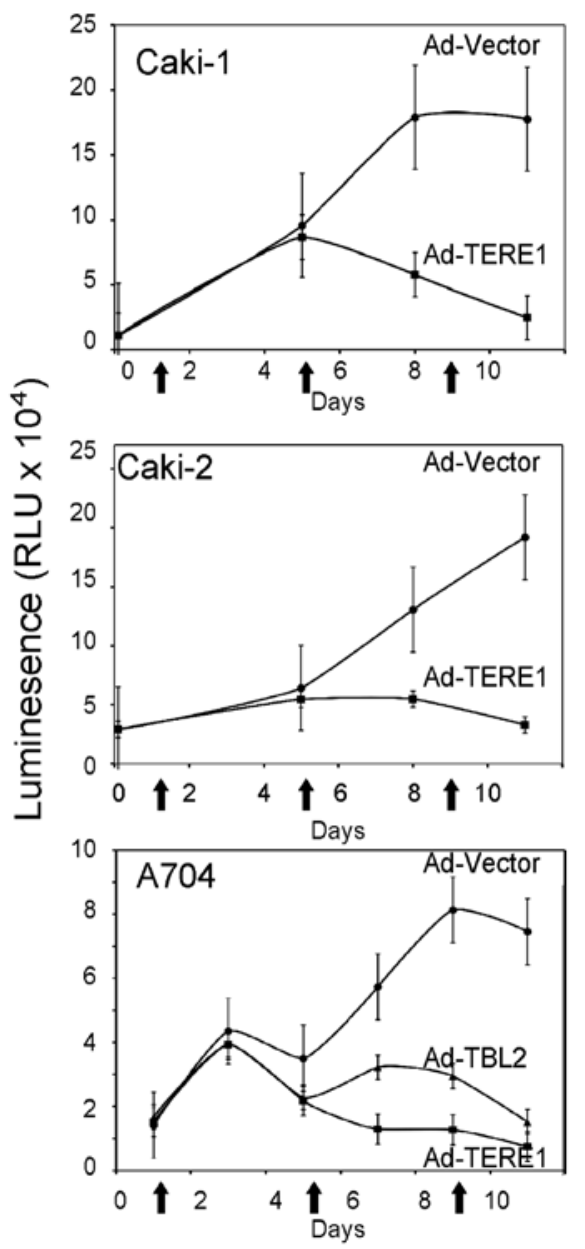

Figure 3. Ectopic TERE1 expression inhibits growth of RCC cell lines. The growth of Caki-1, Caki-2 and A704 renal carcinoma cell lines was evaluated after transduction by Ad-TERE1 cDNA or Ad-LACZ (arrows) over 10 days via the Cell titer-Glo Luminescent Cell viability kit from Promega. Ectopic TERE1 expression inhibited cell growth $>80 \%$ after 5 days. TBL 2 expression caused similar inhibition of A704 cell growth.

(25-27). Caki-1, Caki-2 and A704 renal carcinoma cell lines were transduced with Ad-TERE1 or Ad-LACZ virus (arrows) over 10 days, and proliferation determined via the Cell titer-Glo Luminescent Cell viability kit from Promega. Ectopic TERE1 expression inhibited cell growth up to $80 \%$ in all three of the cell lines after 10 days (Fig. 3). Ectopic TBL2 also inhibited A704 cell growth. TERE1 also caused significant decreases in stable colony formation (Fig. 4B) in Caki-1 (80\%), A498 (45\%), ACHN (38\%), and 786-O (57\%) renal cancer cell lines after lentiviral transduction and selection in blasticidin for 3 weeks, but only a slight decrease in A704 colonies (6\%). Methylene blue stained colonies shown for some cell lines in Fig. 4A. Conversely, TERE1 knockdown increased colony formation: in Caki-1 (1.9-fold), A704 (1.8-fold), A498 (1.5-fold), ACHN (1.7-fold), and 786-O (1.3-fold). A TERE1-mediated increase in caspase $3 / 7$ activity was observed in Caki- 1 (40\% increase), 786-O (60\% increase), and ACHN (20\% increase) cell lines 4 days after Ad-TERE1 transduction. This suggests that a delayed apoptosis plays a role in the TERE1-mediated growth suppression in some of the RCC cells, though may not account for all the growth inhibition. Based on the importance of mitochondrial metabolism in the metabolic phenotype of RCC 

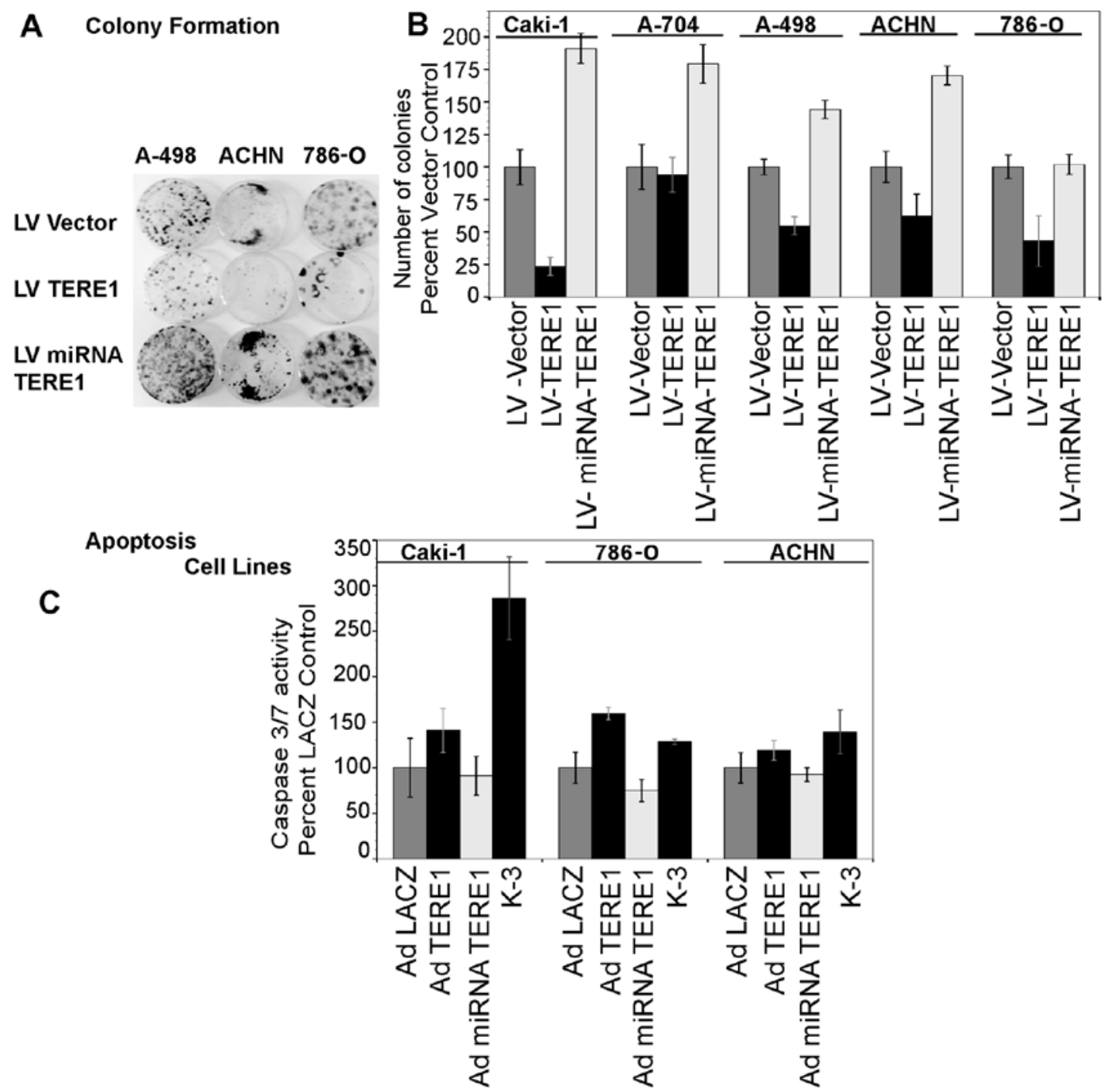

Figure 4. A, TERE1 inhibits colony formation in renal cancer cell lines. RCC cell lines: Caki-1, ACHN, 786-O, and A498 were transduced with either lentiviral, LV: -Vector, -TERE1 cDNA for overexpression, or - miRNA-TERE1 for TERE1-knockdown. Stable colonies were selected in blasticidin for 3 weeks and stained with metheylene blue. B, TERE1 expression inhibits colony formation. TERE1-knockdown increases colony formation. C, Ectopic TERE1 increases caspase 3/7 activity in Caki-1, 786-O, and ACHN cell lines 4 days after Ad-TERE1 transduction.

(19-22), we turned our focus to looking at effects of TERE1 on additional aspects of mitochondrial function.

Extracellular flux analysis. We extended our inquiry into the effects of TERE1 on mitochondrial function via measurements of OCR and proton production, expressed as the ECAR in Caki-1 RCC cells, using a Seahorse Bioscience XF24 extracellular flux analyzer (ECF) (Fig. 5). Comparing the basal OCR responses of Ad-TERE1 and Ad-vector cells, TERE1 increased the OCR over 2-fold $(155 / 70=2.2)$ (left side of top plots in Fig. 5). Next, we injected the proton iontophore FCCP to estimate the maximal potential respiration sustainable by the cells. By disrupting the proton gradient and ATP synthesis, FCCP leads to a rapid consumption of oxygen as cells attempt to use glycolysis to make ATP. FCCP increased the OCR of Ad-vector cells almost 2-fold $(130 / 70=1.86)$ and Ad-TERE1 cells by 1.6 -fold $(246 / 155=1.58)$. Comparing the FCCP-treated Ad-TERE1 to the Ad-vector cells, shows an almost 2-fold increase $(246 / 130=1.9)$. Vitamin K-2 reduced the basal OCR of Ad-vector cells $(34 / 70=0.49)$, but had a negligible effect with Ad-TERE1 cells (149/155=0.96). Similar effects of K-2 were observed in presence of FCCP, suggesting that K-2 treatment exerts some immediate anti-oxidant effects in vector-transduced cells but not TERE1-transduced cells, as if TERE1 expression saturates some component of the maximal potential respiration.

Next, we compared the proton production, ECAR responses of Ad-TERE1 and Ad-vector cells (left side of bottom plots in Fig. 5). TERE1 increased the basal ECAR 1.5-fold $(12 / 8=1.5)$ and the FCCP-induced ECAR 1.4-fold $(25 / 18=1.4)$, relative to Ad-vector cells. ECAR measurements are generally indicative of lactic acid production formed during glycolytic energy metabolism (44), thus the TERE1-induced 1.5-fold ECAR increase suggests that only a portion of the 2-fold TERE1-induced OCR is due to increase in metabolic flux due to glycolysis, the remainder likely is due to other components of OCR. Measurements of OCR represent several concurrent factors including changes in oxidative phosphorylation, non-mitochondrial respiration including oxidative stress, and mitochondrial proton leak, thus 

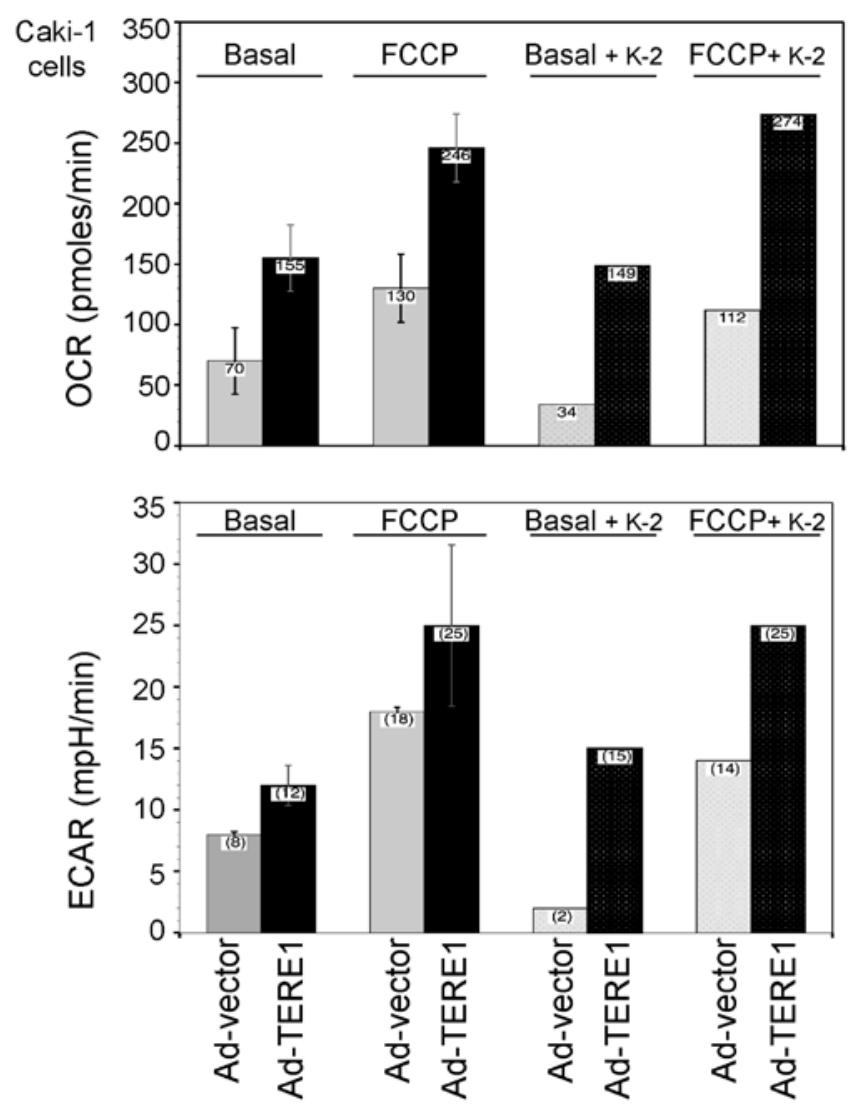

Figure 5. Analysis of $\mathrm{O}_{2}$ consumption and $\mathrm{H}^{+}$production in Caki-1 cells after ectopic TERE1 expression with Ad-TERE1 using a Seahorse Bioscience XF24 Extracellular Flux Analyzer. TERE1 increased the oxygen consumption rate (OCR) and the hydrogen production rate (ECAR). Addition of cyanide p-trifluoromethoxy-phenylhydrazone, FCCP, permitted estimate of the maximal respiration rate. Vitamin K-2 injection showed some anti-oxidant effects.

we examined whether TERE1 would elevate the level of oxidative stress in RCC cells.

TERE1-modulation of oxidative stress. Based on redox-cycling properties of K-2 (45), we evaluated whether TERE1 expression might affect the cellular levels of oxidative stress in Caki-1 and Caki- 2 cells. We conducted imaging of Caki-1 and Caki- 2 cells that had been loaded with dihydrorhodamine 123 or CellROX deep red fluorogenic probes after infection with Ad-LACZ, Ad-TERE1, or pre-incubation with menadione (K-3). Fig. 6 (left side, top green), shows that Ad-TERE1 (1911 FUs) infected Caki-1 cells show an increase of over $18 \%$ in dihydrorhodamine 123 oxidation compared to the control vector, Ad-LACZ infected cells [1616 fluorescence units (FUs)]. In Caki-2 cells dihydrorhodamine 123 oxidation was increased almost 2-fold (3476/1772). Next, we evaluated the effects of TERE1 on CellROX deep red oxidation (Fig. 6, right side, red). Using pretreatments of vitamin $\mathrm{K}-3$ at $30 \mu \mathrm{M}$ or $\mathrm{H}_{2} \mathrm{O}_{2}$ at $100 \mu \mathrm{M}$ for $1 \mathrm{~h}$, as positive controls, we observed significant increases, $44 \%$ and $27 \%$, in Caki-1 and Caki-2 cells, respectively. TERE1 expression caused a modest increase in CellROX oxidation of $14 \%$ in Caki-1, but was decreased by $23 \%$ in Caki- 2 cells. Apparently there are differences in the response to ectopic TERE1 between the two cell lines. Oxidation of both probes increased in Ad-TERE1 infected Caki-1 cells. Caki- 2 cells showed increase only with the dihydrorhodamine 123 probe but not CellROX deep red. Since dihydrorhodamine 123 oxidizes in response to both ROS and RNS, and CellROX deep red oxidation is specific for ROS but not RNS, this suggested the possibility that Caki-2 cells may produce NO in response to TERE1 expression.

Nitric oxide production. We examined whether ectopic TERE1 expression would affect cellular levels of nitric oxide in Caki-1 and Caki-2 RCC cells based on reports that vitamin K-2 could induce iNOS and increase NO production in endothelial cells (46), and NO production in zebrafish models for UBIAD1 (41). We conducted live cell imaging of Caki- 1 and Caki- 2 cells that had been loaded with the DAF-FM-DA fluorogenic probe after infection with Ad-LACZ or Ad-TERE1. We also tested the effects of addition of menaquinone (K-2). DAF FM reacts with $\mathrm{NO}$ and RNS to form a fluorescent benzotriazole. The graph in Fig. 7 compares NO production in Caki-1 (top panel) and Caki-2 (bottom panel) cells. TERE1 reduced the basal cellular NO level in Caki-1 cells, but increased NO in Caki-2 cells. Supplementing with vitamin K-2 increased NO production in Ad-vector and Ad-TERE1 in both cell lines (not shown for Caki-1). Further studies will be needed to determine the basis for the difference in basal NO production between Caki-1 and Caki-2 cells, e.g., whether there may be differences in INOS expression, or NO secretion. Overall, the effects of TERE1 on NO in Caki-2 cells are consistent with a TERE1-mediated K-2 enhancement of mitochondrial respiratory chain to produce NO and other RNS $(24,39,47)$. Next, we turned our focus from mitochondria, to a mechanism of retrograde signaling to the nucleus that is predicted by TERE1-mediated synthesis of K-2 and the activation of SXR nuclear receptor target genes that play a role in lipid metabolism, and cholesterol efflux $(32,33)$.

TERE1, TBL2 and vitamin K-induced changes in cellular cholesterol. Based on the reports of an elevated cholesterol phenotype in RCC cells (11), and its potential to contribute to apoptotic escape during tumor progression (12-16), we evaluated the effect of ectopic TERE1 and TBL2 expression on levels of cholesterol in the Caki-1, Caki-2, and HEK293 embryonic kidney cell lines. Furthermore, given the role of TERE1 in vitamin K-2 synthesis, we tested whether pre-incubation with vitamin $\mathrm{K}$ derivatives would also reduce cellular cholesterol levels. We ectopically expressed TERE1 and TBL2 proteins in Caki-1 and Caki-2 cells via infection with adenoviral vectors, and via plasmid transfection with HEK293 cells. We confirmed expression of the $\sim 37 \mathrm{kDa}$ TERE1 and the $\sim 49 \mathrm{kDa}$ TBL2 protein via immunoblots (Fig. 8). Samples with elevated expression of TERE1 or TBL2 proteins had significantly reduced intracellular cholesterol levels compared to those with the control vector. We also found that that a 72-h treatment of Caki-1 and Caki-2 cells with vitamin $\mathrm{K}-1(30 \mu \mathrm{M}), \mathrm{K}-2(30 \mu \mathrm{M})$, or $\mathrm{K}-3(10 \mu \mathrm{M})$ can reduce cellular cholesterol by at least $50 \%$. This is consistent with a mechanism of K-2 mediated SXR activation of cholesterol efflux $(48,49)$.

TERE1, TBL2-induced changes in SXR target gene expression. Next we explored whether ectopic TERE1 or TBL2 would induce changes in expression of SXR target genes in Caki-1 and Caki-2 cells. SXR has roles in regulation of endobiotic homeostasis, and regulation of transporters involved in xenobiotic clearance 


\section{Caki-1}

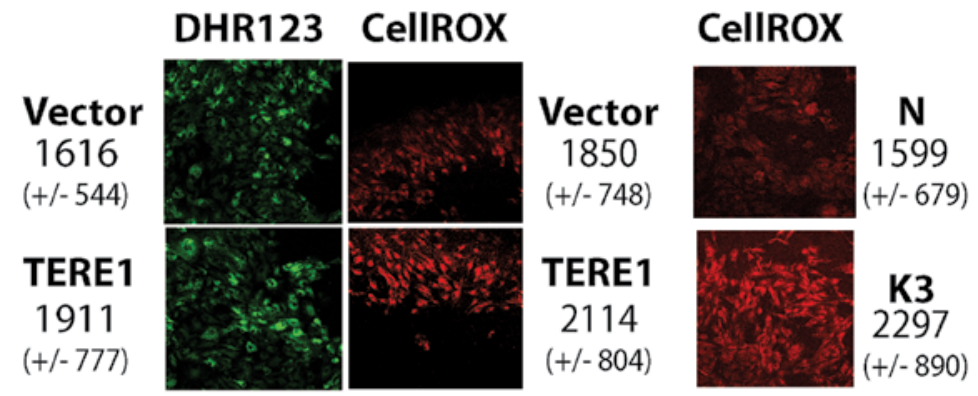

\section{Caki-2}

\section{CellRoX}

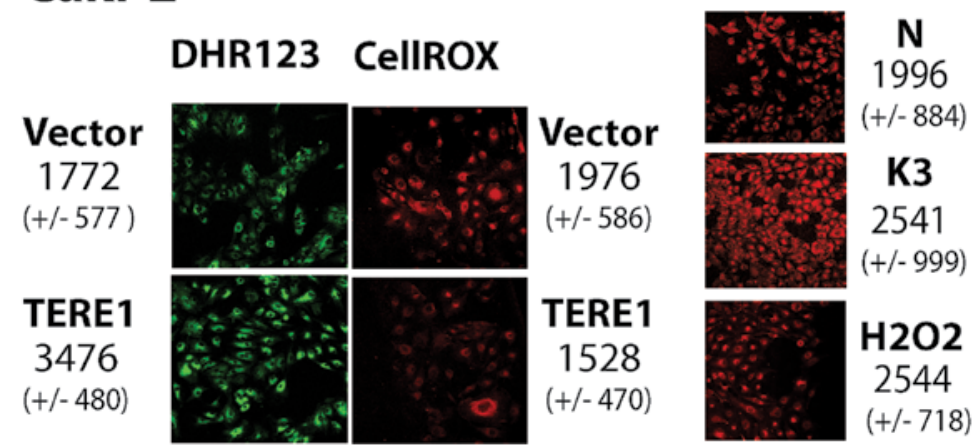

Figure 6. Ectopic TERE1 modulates ROS in Caki-1 and Caki-2 RCC cells. Caki-1 and Caki-2 cells were treated for $60 \mathrm{~h}$ with Ad-LACZ, or Ad-TERE1, or incubated for $1 \mathrm{~h}$ with vitamin $\mathrm{K}-3(30 \mu \mathrm{M})$ or $\mathrm{H}_{2} \mathrm{O}_{2}(100 \mu \mathrm{M})$. Confocal imaging was performed after loading cells with $5 \mu \mathrm{M}$ of CellROX deep red or dihydrorhodamine 123 fluorogenic probes. Cellular fluorescence intensities were quantified after off-cell background subtraction. TERE1 increased oxidation of both probes in Caki-1 but only DHR123 in Caki-2 cells.

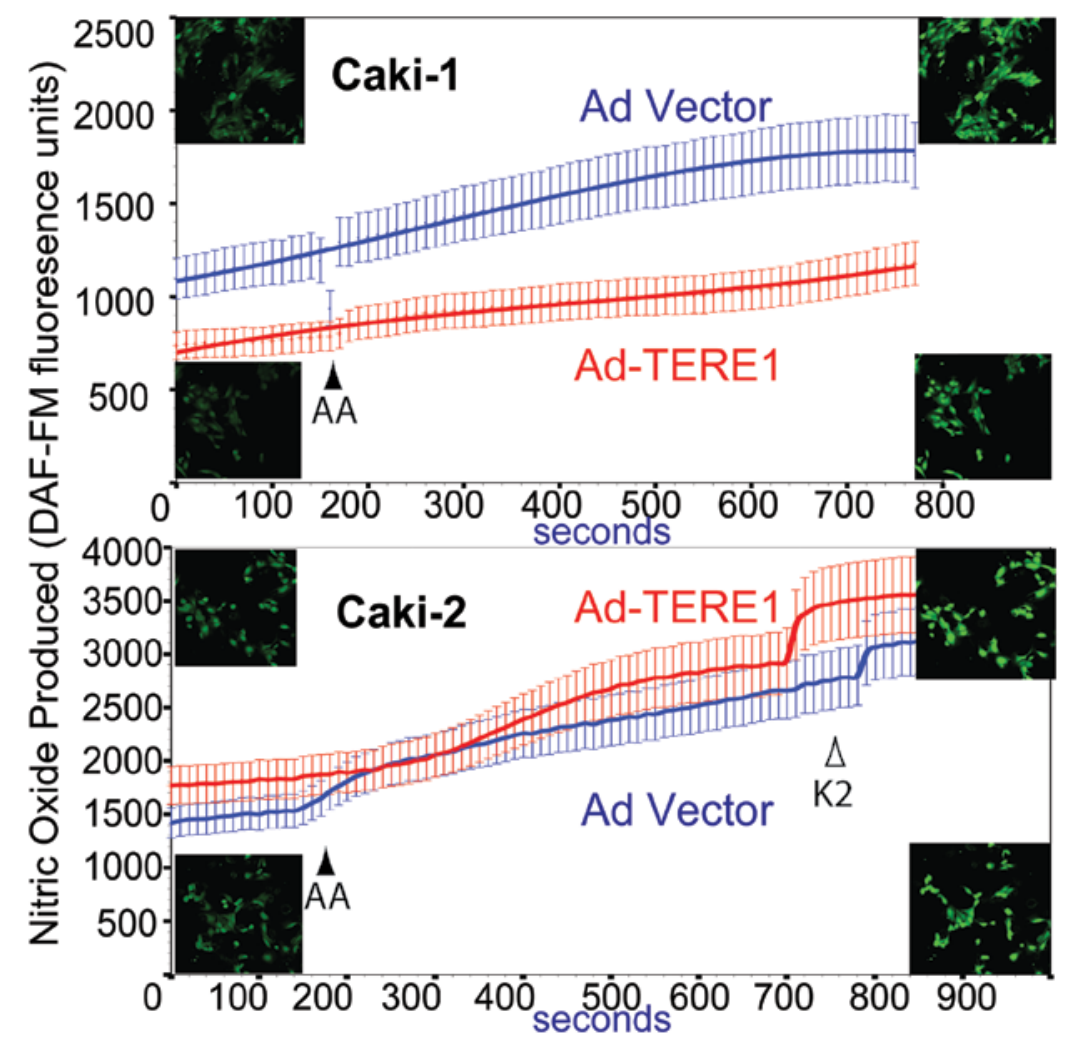

Figure 7. TERE1 modulates nitric oxide production in Caki-1 and Caki-2 RCC cells. Confocal imaging was performed on Caki-1 (top) and Caki-2 (bottom) cells that had been infected for $72 \mathrm{~h}$ with Ad-LACZ or Ad-TERE1 and loaded with DAF-FM-DA which reacts with NO and RNS to form a fluorescent benzotriazole. AA refers to minimal essential medium amino acids added to provide a source of arginine. K-2 refers to addition of vitamin $\mathrm{K}-2$, menaquinone ( $30 \mu \mathrm{M}$ ). Images were captured at 10 -sec intervals. TERE1 increased NO production in Caki-2 cells but not Caki-1 cells. K-2 increased NO in both (not shown for Caki-1). 

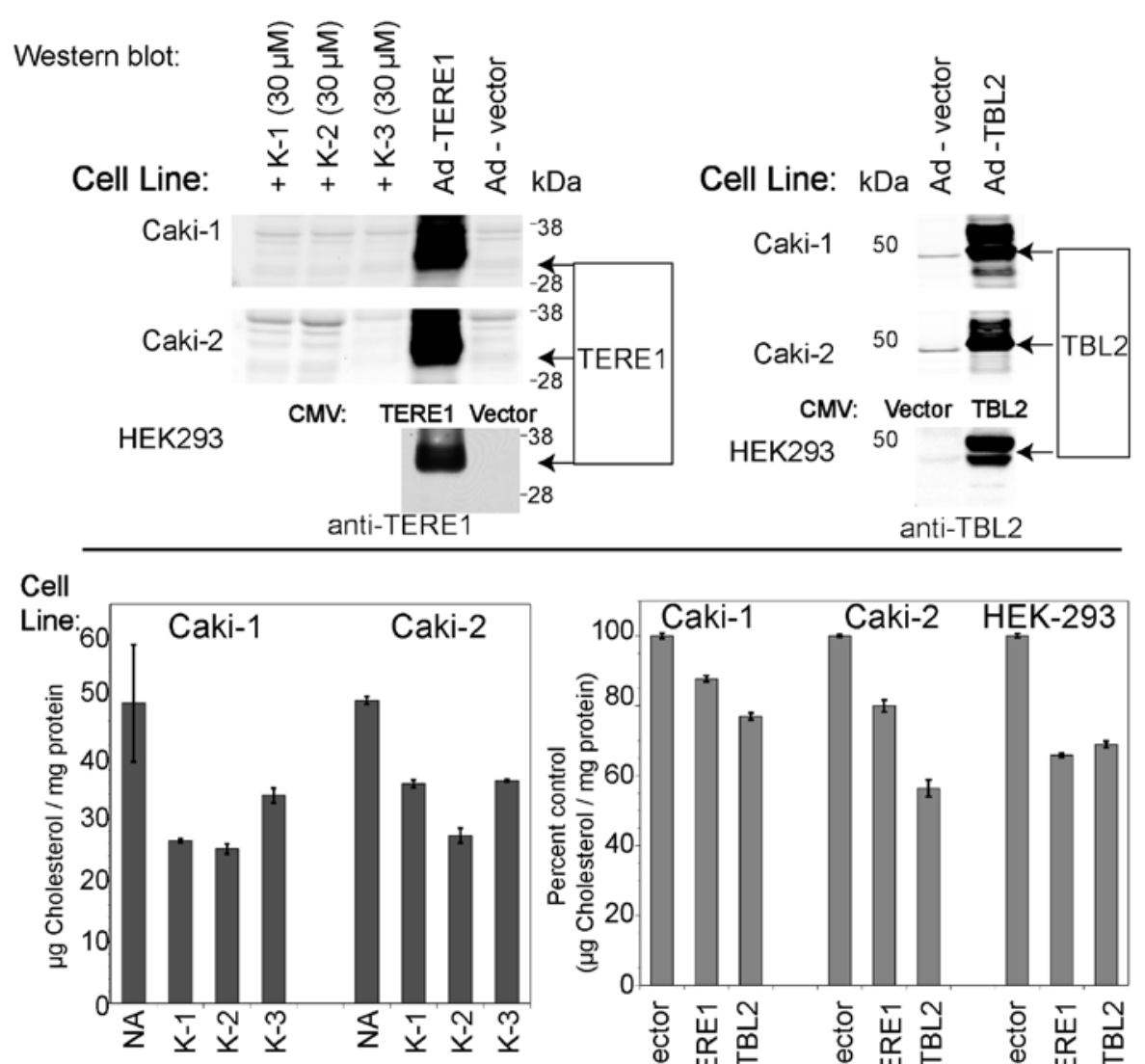

Amplex Red cholesterol assay:

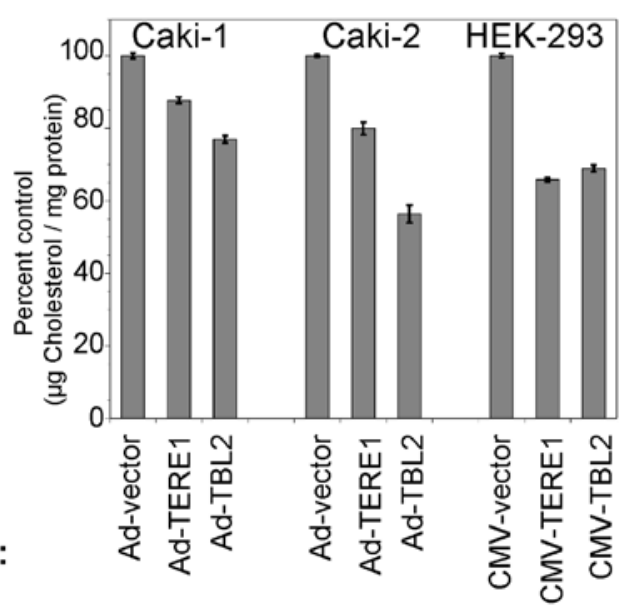

Figure 8. Elevation of TERE1 or TBL2 protein expression reduces cellular cholesterol levels. We ectopically expressed TERE1 and TBL2 proteins in Caki-1, Caki-2, and HEK293 cells and measured cholesterol using the Amplex Red assay. Treatment of cells with vitamin K-1 (30 $\mu \mathrm{M})$, vitamin K-2 (30 $\mu \mathrm{M})$, or vitamin K-3 (10 $\mu \mathrm{M})$ or ectopic expression of TERE1 and TBL2 proteins for $72 \mathrm{~h}$ results in a reduced level of cellular cholesterol compared to untreated or Ad-LACZ vector controls. Expression of the $\sim 37 \mathrm{kDa}$ TERE1 and the $\sim 49 \mathrm{kDa}$ TBL2 proteins was confirmed via immunoblots.

$(32,49)$. We selected established target genes of SXR, of LXR (which can be cross-regulated) and several genes involved in cholesterol synthesis and catabolism (49-56). The Venn diagram in Fig. 9 summarizes our findings and depicts the fold-change in gene expression after TERE1 overexpression (red), or TBL2 overexpression (blue) relative to AD-LACZ and normalized as described in Materials and methods. We have grouped the changes common to both induction treatments, and those found only with each inducer. The main result is that, as predicted, a number of changes were observed in established target genes of SXR (indicated by the asterisk). These include genes involved in transport, synthesis and catabolism of fatty acids: "FASN, ${ }^{*}$ CPT1A, "SCARB1, "SCD1; or cholesterol: *CD36, SREBP1, "HMGCS, "HMGR, FBXW7; or sterol metabolism: "CYP17A1, ${ }^{*}$ CYP24A1, "CYP7B1, CYP11A1. We also observed similar changes in some SXR targets after TERE1 expression $(+361)$ in Caki-2 cells. These include *ABCB1 (+23.4), ${ }^{*} \mathrm{CD} 36(+1.9)$, ${ }^{*} \mathrm{CPT} 1 \mathrm{~A}(+1.4),{ }^{*} \mathrm{CYP} 11 \mathrm{~A} 1(+1.6),{ }^{*} \mathrm{CYP} 24 \mathrm{~A} 1(+2),{ }^{\circ} \mathrm{CYP} 3 \mathrm{~A} 4$ $(+2),{ }^{*}$ CYP7A1 (+1.8), FBXW7 (+7.1), FDPS (+2), "INSIG1 $(+21.7)$, "SCARB1 (+2.0), *SCD1 (+1.7), SREBP1 (+2.4), SREBP2 (+3.9), STAR (+9.9), and TSPO (+53). Notably several of these targets in Caki-2 play a role in cholesterol transport to mitochondria (CYP11A1, STAR, TSPO) and may be involved in cholesterol mobilization for oxysterol formation (57). It is

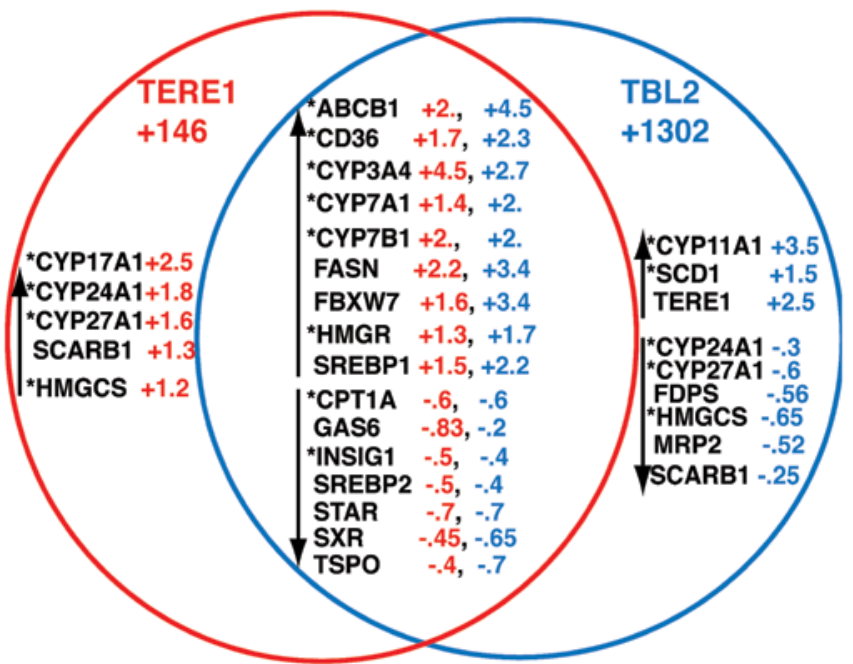

Fold changes by Fluidigm Taqman RTPCR

Figure 9. TERE1 and TBL2 alter lipid metabolism and SXR target gene expression in Caki-1 RCC cells. The Venn diagram depicts the fold-change in expression of established SXR target genes (indicated by the asterisk) by Fluidigm RT-PCR TaqMan expression assays of Caki-1 cells after TERE1 overexpression (red), and TBL2 overexpression (blue) relative to AD-LACZ or parental cell control and normalized as described in Mateterials and methods. The data support the induction of changes in expression of known SXR target genes in cholesterol and fatty acid regulation. 


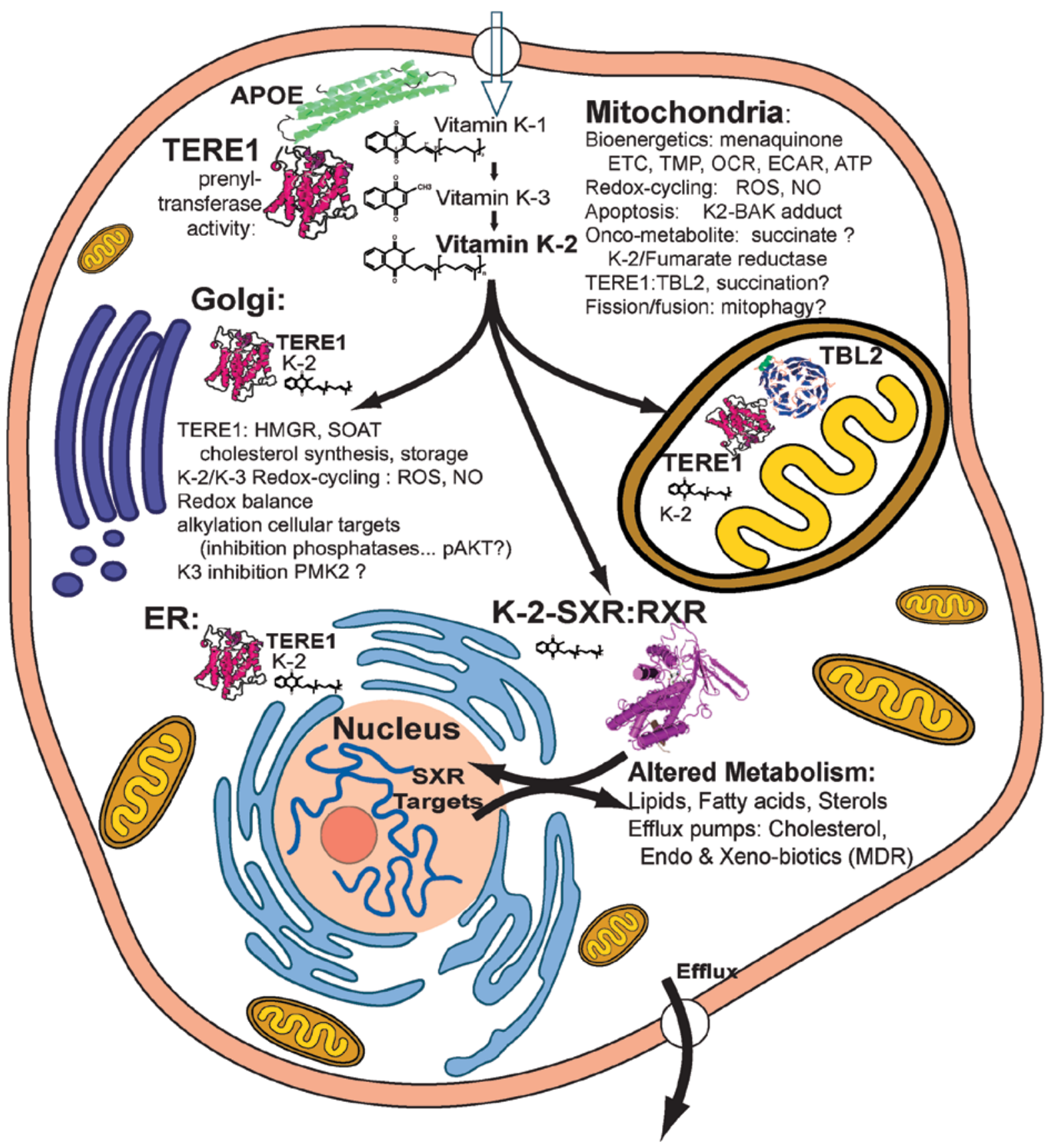

Figure 10. Overview of TERE1, vitamin K-2/K-3-mediated effects on cellular metabolism. APOE is a carrier of vitamin K-1, cholesterol, and triglycerides that interacts with TERE1 and is involved in K-1 delivery as well as lipid recycling. TERE1 converts K-1 to K-2 at multiple locations: golgi, ER, and mitochondria. In ER and golgi TERE1 may interact with HMGR and SOAT1 thus affect cholesterol synthesis and storage. Based on redox-cyling K-2 and K-3 create reactive oxygen species, ROS, and nitic oxide, NO. Depending on the cellular anti-oxidant milieu, TERE1 may serve as a pro- or anti-oxidant. In mitochondria K-2 plays a role in the electron transport chain, ETC, and can elevate the transmembrane potential, TMP, increase $\mathrm{O}_{2}$ consumption and $\mathrm{H}^{+}$production rates, OCR and ECAR, and ATP. TERE1 can increase apoptosis, which may involve K-2 adduction with BAK. K-2 may drive fumarate reductase and lead to succinate elevation. Elevated succinate is an onco-metabolite that leads to succination of proteins such as the TERE1 interacting protein, TBL2. K-2 is a potent activator of the SXR nuclear receptor, which traverses to the nucleus with RXR and is a master regulator of lipid and fatty acid homeostasis, energy metabolism, and phase I and II enzymes and transporters involved in drug metabolism/clearance, and efflux of cholesterol. Overall, these findings highlight the potential relevance of TERE1 expression in tumor cell bioenergetics, oxidative and nitrosative stress, and suggest a possible role for TERE1 in the adaptation to hypoxic microenvironments and invasiveness.

interesting that TERE1 increases expression of CYP24A1 whose expression is typically lost in RCC and is required for transformation of vitamin D3. Overall, these data demonstrate that TERE1 expression can lead to regulation of SXR target genes involved in lipid metabolism and are consistent with the hypothesis that this is due to activation of SXR by TERE1mediated synthesis of K-2 $(23,48,49)$.

\section{Discussion}

TERE1 expression in RCC and suppression of growth in vitro. Our objectives with this study were to explore a possible role for TERE1 in RCC. Given our previous demonstration of TERE1mediated cholesterol modulation in bladder cancer cells $(24,27)$ our interest was driven by the emerging understanding of RCC 
as a disease of elevated cholesterol and an altered metabolic phenotype $(4,8,11)$. We first examined TERE1 expression in a TMA panel of RCC specimens and found that TERE1 staining was absent or low in almost $60 \%$ of RCC specimens; hence, may represent a significant phenotype in renal cancer. Next we evaluated growth upon ectopic TERE1 expression and found cell growth inhibited by up to $80 \%$ in Caki-1, Caki-2, and A704 renal carcinoma cell lines after 10 days. Furthermore, TERE1 expression caused significant reduction in stable colony formation in several renal cancer cell lines. It is significant that miRNA-mediated-TERE1 knockdown generally increased the number of colonies, further supporting the idea that a reduced TERE1 level may contribute to RCC progression. We then proceeded to evaluate effects of TERE1 related to mitochondrial function: apoptosis, $\mathrm{O}_{2}$ consumption, and ROS/RNS production, and also examine predicted effects on SXR target gene expression and cholesterol levels based on K-2 functioning as a ligand for SXR nuclear receptor signaling. The schematic in Fig. 10 outlines some of the mechanisms described in the literature by which TERE1 and K-2 may affect RCC growth or tumor progression for this discussion.

Ectopic TERE1 increases apoptosis in RCC cell lines. As an indicator of apoptosis, we examined caspase 3/7 activity after Ad-TERE1 transduction and found increases in RCC cell lines: Caki-1 (by 40\%), 786-O (by 60\%), and ACHN (by 20\%). This is consistent with reports of growth inhibition, autoschizis, necrosis, or a delayed apoptosis in different tumor cell lines in response to vitamin K-2 and K-3 (34,58-60). Recently K-2 was found to form covalent adducts with the Bcl-2 homologous antagonist killer protein, BAK, and induce BAK-mediated apoptosis (61). This facilitation of BAK activity by K-2 adduction is in contrast to thiol arylation adducts of K-3 that inactivate phosphatases. K-2 adduction suggests a possible mechanism for the TERE1-mediated apoptosis we observed in $\mathrm{RCC}$ cell lines, and raises the possibility of K-2 adduct formation with other targets, especially, TERE1-interacting proteins. Overall, TERE1-mediated K-2 synthesis has multiple possible mechanisms capable of affecting cell growth, which may account for some of the differences observed between the cell lines. Although ectopic expression likely exaggerates TERE1mediated effects, the apparent liability TERE1 poses to RCC cell growth, may account for its low level or absence in over half of the RCC tumor specimens and cell lines.

TERE1 effects on mitochondrial oxygen and hydrogen flux. Based on the paradigm of altered mitochondrial metabolism in RCC, we analyzed two parameters of mitochondrial activity in Caki-1 and Caki-2 RCC cells: oxygen consumption, OCR, and hydrogen production, ECAR. We found that TERE1 significantly increased the basal and maximal rates of oxygen consumption and hydrogen production. Our findings are consistent with the reported role of vitamin K-2 in mitochondrial electron transport and ATP production and the mitochondrial functionality of TERE1 we inferred via co-localization with mitochondrial TBL2 (39). Changes in OCR measurements may reflect changes in oxidative phosphorylation, non-mitochondrial respiration including oxidative stress, and mitochondrial proton leak (62). Based on the fact that the electron transport chain is an abundant source of mitochondrial superoxide radicals $(34,37,45,63)$, we examined ROS and RNS effects of TERE1.

TERE1 effects on ROS/RNS. To evaluate whether TERE1 would elevate the level of oxidative stress in Caki-1 and Caki-2 RCC cells, we compared oxidation of CellROX deep red, specific for ROS, and dihydrorhodamine 123 , affected by either ROS or RNS. TERE1 increased oxidation of both fluorogenic probes in Caki-1 cells, implying an increase in ROS. Caki- 2 cells showed an increase in dihydrorhodamine 123 oxidation, but a $23 \%$ decrease in CellROX oxidation, implying RNS, but not ROS. We then confirmed that Caki- 2 cells do increase NO production in response to ectopic TERE1 expression, but in Caki-1 cells, TERE1 reduced basal NO levels. Given that many variables may influence the levels and cellular consequences of ROS and RNS: TERE1 expression level and activity, substrate availability, subcellular location, prevailing oxygen tension, activity of cellular antioxidants, and reducing enzymes $(37,64,65)$, it is not surprising to observe differences between cell lines. ROS/ RNS signaling cross-talks with many critical cellular functions, including autophagy, mitophagy, fatty acid metabolism and the dosage/activity of TERE1 that may trigger different types of signaling is uncharacterized (66-68). One implication of TERE1 effects on oxidative stress is that the heterogeneous expression of TERE1 in RCC specimens may be a contributing factor to heterogeneous $\mathrm{O}_{2}$ tension and inflammatory cytokine production that has been reported to be associated with invasion potential of RCC $(69,70)$. TERE1 undoubtedly has complex effects on tumor cell populations.

Metabolic implications of TERE1 and $K-2 / K-3$ in tumor cells. There is important incentive to understand the mechanisms by which TERE1 dosage affects metabolism, growth signaling and tumor progression. Numerous reports describe K-2 and K-3 mediated inhibition of tumor cell growth and the basis of the differences in some of their effects; e.g., it has been reported that K-3 but not K-2 can arylate thiols (34-36,63,71). Research is focused on designing vitamin $\mathrm{K}$ analogs that may distinguish the different mechanisms and offer therapeutic advantage. Interestingly, more highly prenylated forms of K-2 were found to be better SXR activators (72,73). These studies should guide the clarification of which activities contribute to the tumor suppressor activity of TERE1 in RCC. One relevant possibility concerns the proposed two-step mechanism of TERE1-mediated conversion of phylloquinone, $\mathrm{K}-1$, to menaquinone, $\mathrm{K}-2$, with menadione, $\mathrm{K}-3$, as an intermediate (23). The presence of $\mathrm{K}-3$ presents a possible mechanism for TERE1 to affect the glycolytic pyruvate kinase isoenzyme PKM2, which is highly relevant to the altered metabolic phenotype of RCC. PMK2 has an emerging role as a dominant regulator of tumor cell glycolysis and is the major pyruvate kinase isoform in RCC $(20,74,75)$. PKM2 catalyzes the dephosphorylation of phosphoenolpyruvate to pyruvate, hence, is responsible for oxygen-independent net ATP production that allows survival of the cells under hypoxic conditions as are often found in solid tumors. PMK2 can be inhibited by vitamin $\mathrm{K}-3$, and to a lesser degree by $\mathrm{K}-2$, as well as by $\operatorname{ROS}(76,77)$. This implies that a reduction in TERE1 levels in RCC could reduce the generation of the inhibitory K-3 intermediate and may lead to a greater activity of PKM2, enhancing glycolytic 
flux and tumor growth. Considering the role of menaquinone in anaerobic organisms, an alternate possibility is that tumor cells with low levels of TERE1 and menaquinone may be selected against in hypoxic environments and driven to invade.

TERE1 and mitochondrial ETC. Given the predominant role of ubiquinone in oxidative respiration, the role that menaquinone plays in mitochondrial electron transfer is not well understood. However, menaquinone has an established electron carrier role in the ETC of anaerobic bacteria and anaerobic mitochondria, and there is increasing evidence regarding its possible role in tumor mitochondria $(37,38,78,79)$. In addition to the well known NADH-ubiquinone reductase activity of mitochondrial complex I typical of aerobic respiration, there is also a NADHfumarate reductase anaerobic electron transport system in mitochondria which is capable of using menaquinone to donate electrons to run a reverse TCA conversion of fumarate to succinate $(80,81)$. Elevation of TCA intermediates, fumarate and succinate, due to inactivation or deficiency of fumarate hydratase in RCC serves as a prototypical onco-metabolic mechanism leading to HIF $\alpha$ stabilization that is a major driving force of RCC $(22,82,83)$. Elevated succinate can also lead to a novel post-translational modification called succination (84), and the TERE1-interacting mitochondrial protein, TBL2, has been identified as a substrate for succination in RCC cells, although the consequence of this alteration is unknown.

TBL2. Except for the interaction with TERE1, little is known about the role of TBL2 except it has appeared in protein interaction databases as a partner with SMURF1 or PDK1 suggesting a possible role in TGF $\beta$, and/or AKT signaling, respectively $(85,86)$. The TBL2 gene was originally indentified within a region of chromosome 7q11.23 deleted in Williams-Beuren syndrome (87). There are numerous studies evaluating the relationship between mitochondrial WD repeat proteins involved in mitochondrial fission/fusion $(88,89)$ and oxidative stress and mitophagy $(67,90)$. It is interesting to speculate that the WD repeats of TBL2, may be involved in similar functions. We have found that ectopic TBL2 expression, like TERE1, can increase mitochondrial transmembrane potential, elevate oxidative and nitrosative stress in bladder cancer cells $(24,27)$ and have now confirmed its potential for modulation of cholesterol in RCC cell lines.

TERE1, TBL2, and modulation of cholesterol and SXR target genes. In this study, we confirmed that ectopic expression of TERE1 or TBL2 can reduce cellular cholesterol levels in Caki-1, Caki-2, and HEK293 cell lines. Similar cholesterol reductions were observed with application of vitamin K-1, K-2, and K-3. Recently, cholesterol-binding and cholesterol regulatory functions were described for both TERE1 and TBL2, supporting our earlier conclusions pointing to their role as modulators of lipid metabolism $(43,91)$. We analyzed TERE1-induced changes in expression of established SXR target genes in Caki-1 and Caki-2 cells and confirmed that SXR target genes involved in cholesterol efflux and fatty acid metabolism are modulated by TERE1 and TBL2. Several of these genes play a role in mobilization or efflux of cholesterol thus may contribute to the TERE1- or TBL2-mediated cholesterol reduction: CD36, ABCB1, and SCARB1 (92-95). CYP27A1 and CYP7A1 oxidize cholesterol for cellular export (96). The ubiquitin ligase FBXW7 is known to degrade SREBP $(97,98)$, which may also lower cholesterol synthesis. SCD1 is an SXR target gene that is known to regulate biosynthesis of unsaturated fatty acids that are used in a variety of phospholipids, triglycerides, and cholesterol esters and can affect fatty acid oxidation (99). The elevation of SCD1 by ectopic TBL2 may be relevant to the proposed role of TBL2 as a candidate gene in triglyceride disorders $(100,101)$. The mechanisms that govern TBL2 in these activities are undefined, however; by virtue of its inner mitochondrial membrane localization and association with TERE1, a role in retrograde signaling should be explored, especially since succinated-TBL2 has been found in the nucleus. Overall these changes in expression of SXR target genes support the hypothesis of SXR activation by TERE1 and modulation of lipid homeostasis via cholesterol efflux and catabolism. This analysis will serve to guide further study of protein expression and signaling in $\operatorname{RCC}(33,48,102)$.

In conclusion, our aim was to establish links between the altered metabolic phenotype of RCC and functionality of the TERE1 prenyltransferase. We have reported a TERE1-negative expression phenotype in a over half of the lesions from a tumor microarray (TMA) set of human RCC tumor specimens, and demonstrated that ectopic TERE1 expression profoundly decreased growth, suppressed colony forming ability, and increased caspase 3/7 activity in a panel of RCC cell lines. We show TERE1 activates mitochondrial activity using extracellular flux analysis and leads to elevations in ROS/RNS. TERE1 and TBL2 reduced Caki-1 and Caki-2 cell cholesterol and activated a common set of SXR target genes with roles in cholesterol and lipid metabolism. We discuss several hypotheses to relate possible TERE1/K-2/K-3 mediated mechanisms of tumor suppression to the altered metabolic phenotype of RCC. Tumor progression depends on adaptations to maintain an elevated oxidative stress level; however, tumor cells must manage oxidative stress levels below the apoptotic threshold (103). In this regard, subversion of apoptotic signaling by elevated mitochondrial cholesterol is highly relevant (104-110). The natural TERE1-mediated targeting of vitamin K-2 synthesis to mitochondria may represent a form of oxidative stress liability to tumor cell metabolism during progression. The loss of TERE1 expression in RCC may be a defect in mitochondrial to nuclear SXR signaling that tumors use to uncouple vitamin K-mediated oxidative stress signaling from apoptosis or negative growth signaling by elevation of cholesterol.

\section{Acknowledgements}

We thank the Veterans Administration Merit Review and the Veterans Affairs Medical Center Philadelphia for the grant support to S.B.M. We thank the Nicolo Family Renal Cancer Research Fund Foundation for their generous support to S.B.M. and WJ.F.

\section{References}

1. Li L and Kaelin WG Jr: New insights into the biology of renal cell carcinoma. Hematol Oncol Clin North Am 25: 667-686, 2011.

2. Messer J, Drabick J and Kaag M: Rational therapy for renal cell carcinoma based on its genetic targets. Adv Exp Med Biol 779: 291-308, 2013.

3. Pischon T, Nöthlings U and Boeing H: Obesity and cancer. Proc Nutr Soc 67: 128-145, 2008. 
4. Drabkin HA and Gemmill RM: Obesity, cholesterol, and clear-cell renal cell carcinoma (RCC). Adv Cancer Res 107: 39-56, 2010.

5. Baldewijns MM, van Vlodrop IJ, Vermeulen PB, Soetekouw PM, van Engeland M and De Bruine AP: VHL and HIF signalling in renal cell carcinogenesis. J Pathol 221: 125-138, 2010.

6. Keith B, Johnson RS and Simon MC: HIF1alpha and HIF2alpha: sibling rivalry in hypoxic tumour growth and progression. Nat Rev Cancer 12: 9-22, 2012.

7. Banumathy G and Cairns P: Signaling pathways in renal cell carcinoma. Cancer Biol Ther 10: 658-664, 2010.

8. Linehan WM, Bratslavsky G, Pinto PA, et al: Molecular diagnosis and therapy of kidney cancer. Annu Rev Med 61: 329-343, 2010.

9. Mihaly Z, Sztupinszki Z, Surowiak P and Gyorffy B: A comprehensive overview of targeted therapy in metastatic renal cell carcinoma. Curr Cancer Drug Targets 12: 857-872, 2012.

10. Pal SK, Williams S, Josephson DY, Carmichael C, Vogelzang NJ and Quinn DI: Novel therapies for metastatic renal cell carcinoma: efforts to expand beyond the VEGF/mTOR signaling paradigm. Mol Cancer Ther 11: 526-537, 2012.

11. Gebhard RL, Clayman RV,Prigge WF, et al: Abnormal cholesterol metabolism in renal clear cell carcinoma. J Lipid Res 28: 1177-1184, 1987.

12. Christenson E, Merlin S, Saito M and Schlesinger P: Cholesterol effects on BAX pore activation. J Mol Biol 381: 1168-1183, 2008

13. Li YC, Park MJ, Ye SK, Kim CW and Kim YN: Elevated levels of cholesterol-rich lipid rafts in cancer cells are correlated with apoptosis sensitivity induced by cholesterol-depleting agents. Am J Pathol 168: 1107-1118, 2006.

14. Martinez-Abundis E, Garcia N, Correa F, Franco M and Zazueta C: Changes in specific lipids regulate BAX-induced mitochondrial permeability transition. FEBS J 274: 6500-6510, 2007.

15. Oh HY, Lee EJ, Yoon S, Chung BH, Cho KS and Hong SJ: Cholesterol level of lipid raft microdomains regulates apoptotic cell death in prostate cancer cells through EGFR-mediated Akt and ERK signal transduction. Prostate 67: 1061-1069, 2007.

16. Swinnen JV, Brusselmans K and Verhoeven G: Increased lipogenesis in cancer cells: new players, novel targets. Curr Opin Clin Nutr Metab Care 9: 358-365, 2006

17. Prenen H, Gil T and Awada A: New therapeutic developments in renal cell cancer. Crit Rev Oncol Hematol 69: 56-63, 2009.

18. Srinivasan R, Armstrong AJ, Dahut W and George DJ: Antiangiogenic therapy in renal cell cancer. BJU Int 99: 1296-1300, 2007.

19. Selak MA, Armour SM, MacKenzie ED, et al: Succinate links TCA cycle dysfunction to oncogenesis by inhibiting HIF-alpha prolyl hydroxylase. Cancer Cell 7: 77-85, 2005.

20. Ashrafian H, O'Flaherty L, Adam J, et al: Expression profiling in progressive stages of fumarate-hydratase deficiency: the contribution of metabolic changes to tumorigenesis. Cancer Res 70 : 9153-9165, 2010.

21. O'Flaherty L, Adam J, Heather LC, et al: Dysregulation of hypoxia pathways in fumarate hydratase-deficient cells is independent of defective mitochondrial metabolism. Hum Mol Genet 19: 3844-3851, 2010

22. Yang Y, Valera VA, Padilla-Nash HM, et al: UOK 262 cell line, fumarate hydratase deficient (FH-/FH-) hereditary leiomyomatosis renal cell carcinoma: in vitro and in vivo model of an aberrant energy metabolic pathway in human cancer. Cancer Genet Cytogenet 196: 45-55, 2010.

23. Nakagawa K, Hirota Y, Sawada N, et al: Identification of UBIAD1 as a novel human menaquinone-4 biosynthetic enzyme. Nature 468: 117-121, 2010.

24. Fredericks WJ,McGarvey T, Wang H, et al: The TERE1 (UBIAD1) bladder tumor suppressor protein interacts with mitochondrial TBL2: regulation of trans-membrane potential, oxidative stress and SXR signaling to the nucleus. J Cell Biochem doi: 10.1002/ jcb.24567, 2013 [Epub ahead of print].

25. McGarvey TW, Nguyen T, Tomaszewski JE, Monson FC and Malkowicz SB: Isolation and characterization of the TERE1 gene, a gene down-regulated in transitional cell carcinoma of the bladder. Oncogene 20: 1042-1051, 2001.

26. McGarvey TW, Nguyen T, Puthiyaveettil R, Tomaszewski JE and Malkowicz SB: TERE1, a novel gene affecting growth regulation in prostate carcinoma. Prostate 54: 144-155, 2003.

27. Fredericks WJ, McGarvey T, Wang H, et al: The bladder tumor suppressor protein TERE1 (UBIAD1) modulates cell cholesterol: implications for tumor progression. DNA Cell Biol 30: 851-864, 2011.

28. McGarvey TW, Nguyen TB and Malkowicz SB: An interaction between apolipoprotein $\mathrm{E}$ and TERE1 with a possible association with bladder tumor formation. J Cell Biochem 95: 419-428, 2005.
29. Weiss JS, Kruth HS, Kuivaniemi H, et al: Mutations in the UBIAD1 gene on chromosome short arm 1, region 36, cause Schnyder crystalline corneal dystrophy. Invest Ophthalmol Vis Sci 48: 5007-5012, 2007

30. Nickerson ML, Kostiha BN, Brandt W, et al: UBIAD1 mutation alters a mitochondrial prenyltransferase to cause Schnyder corneal dystrophy. PLoS One 5: e10760, 2010.

31. Nickerson ML, Bosley AD, Weiss JS, et al: The UBIAD1 prenyltransferase links menaquione-4 synthesis to cholesterol metabolic enzymes. Hum Mutat 34: 317-329, 2013.

32. Ihunnah CA, Jiang M and Xie W: Nuclear receptor PXR, transcriptional circuits and metabolic relevance. Biochim Biophys Acta 1812: 956-963, 2011

33. Zhou C, Verma S and Blumberg B: The steroid and xenobiotic receptor (SXR), beyond xenobiotic metabolism. Nucl Recept Signal 7: e001, 2009.

34. Lamson DW and Plaza SM: The anticancer effects of vitamin K. Altern Med Rev 8: 303-318, 2003.

35. Nishikawa Y, Wang Z, Kerns J, Wilcox CS and Carr BI: Inhibition of hepatoma cell growth in vitro by arylating and non-arylating $\mathrm{K}$ vitamin analogs. Significance of protein tyrosine phosphatase inhibition. J Biol Chem 274: 34803-34810, 1999.

36. Gilloteaux J, Jamison JM, Neal DR, Loukas M, Doberzstyn T and Summers JL: Cell damage and death by autoschizis in human bladder (RT4) carcinoma cells resulting from treatment with ascorbate and menadione. Ultrastruct Pathol 34: 140-160, 2010.

37. Nowicka B and Kruk J: Occurrence, biosynthesis and function of isoprenoid quinones. Biochim Biophys Acta 1797: 1587-1605, 2010.

38. Tielens AG, Rotte C, van Hellemond JJ and Martin W: Mitochondria as we don't know them. Trends Biochem Sci 27: 564-572, 2002.

39. Vos M, Esposito G, Edirisinghe JN, et al: Vitamin K2 is a mitochondrial electron carrier that rescues pink1 deficiency. Science 336: 1306-1310, 2012

40. Spurgeon SL, Jones RC and Ramakrishnan R: High throughput gene expression measurement with real time PCR in a microfluidic dynamic array. PLoS One 3: e1662, 2008.

41. Mugoni V, Postel R, Catanzaro V, et al: Ubiad1 is an antioxidant enzyme that regulates eNOS activity by CoQ10 synthesis. Cell 152: 504-518, 2013.

42. Jamin N, Neumann JM, Ostuni MA, et al: Characterization of the cholesterol recognition amino acid consensus sequence of the peripheral-type benzodiazepine receptor. Mol Endocrinol 19: 588-594, 2005

43. Hulce JJ, Cognetta AB, Niphakis MJ, Tully SE and Cravatt BF: Proteome-wide mapping of cholesterol-interacting proteins in mammalian cells. Nat Methods 10: 259-264, 2013.

44. Wu M, Neilson A, Swift AL, et al: Multiparameter metabolic analysis reveals a close 1 link between attenuated mitochondrial bioenergetic function and enhanced glycolysis dependency in human tumor cells. Am J Physiol Cell Physiol 292: C125-C136, 2007.

45. Klaus V, Hartmann T, Gambini J, et al: 1,4-Naphthoquinones as inducers of oxidative damage and stress signaling in $\mathrm{HaCaT}$ human keratinocytes. Arch Biochem Biophys 496: 93-100, 2010.

46. Sano M, Fujita H, Morita I, Uematsu H and Murota S: Vitamin K2 (menatetrenone) induces iNOS in bovine vascular smooth muscle cells: no relationship between nitric oxide production and gammacarboxylation. J Nutr Sci Vitaminol (Tokyo) 45: 711-723, 1999.

47. Bhalerao S and Clandinin TR: Cell biology. Vitamin K2 takes charge. Science 336: 1241-1242, 2012.

48. Shearer MJ and Newman P: Metabolism and cell biology of vitamin K. Thromb Haemost 100: 530-547, 2008.

49. Zhou C, King N, Chen KY and Breslow JL: Activation of PXR induces hypercholesterolemia in wild-type and accelerates atherosclerosis in apoE deficient mice. J Lipid Res 50: 2004-2013, 2009.

50. Landes N: Homologous metabolic and gene activating routes for vitamins E and K. Mol Aspects Med 24: 337-344, 2003.

51. Lim YP and Huang JD: Interplay of pregnane X receptor with other nuclear receptors on gene regulation. Drug Metab Pharmacokinet 23: $14-21,2008$

52. Brown AJ and Jessup W: Oxysterols: sources, cellular storage and metabolism, and new insights into their roles in cholesterol homeostasis. Mol Aspects Med 30: 111-122, 2009.

53. Sonoda J, Chong LW, Downes M, et al: Pregnane X receptor prevents hepatorenal toxicity from cholesterol metabolites. Proc Natl Acad Sci USA 102: 2198-2203, 2005.

54. Wang Y, Rogers PM, Su C, Varga G, Stayrook KR and Burris TP: Regulation of cholesterologenesis by the oxysterol receptor, LXRalpha. J Biol Chem 283: 26332-26339, 2008. 
55. Wang $X$ and Rader DJ: Molecular regulation of macrophage reverse cholesterol transport. Curr Opin Cardiol 22: 368-372, 2007.

56. Wang X, Collins HL, Ranalletta M, et al: Macrophage ABCA1 and ABCG1, but not SR-BI, promote macrophage reverse cholesterol transport in vivo. J Clin Invest 117: 2216-2224, 2007.

57. Lordan S, Mackrill JJ and O'Brien NM: Oxysterols and mechanisms of apoptotic signaling: implications in the pathology of degenerative diseases. J Nutr Biochem 20: 321-336, 2009.

58. Shibayama-Imazu T, Aiuchi T and Nakaya K: Vitamin K2mediated apoptosis in cancer cells: role of mitochondrial transmembrane potential. Vitam Horm 78: 211-226, 2008.

59. Jamison JM, Gilloteaux J, Nassiri MR, Venugopal M, Neal DR and Summers JL: Cell cycle arrest and autoschizis in a human bladder carcinoma cell line following Vitamin C and Vitamin K3 treatment. Biochem Pharmacol 67: 337-351, 2004.

60. Jamison JM, Gilloteaux J, Perlaky L, et al: Nucleolar changes and fibrillarin redistribution following apatone treatment of human bladder carcinoma cells. J Histochem Cytochem 58: 635-651, 2010.

61. Karasawa S, Azuma M, Kasama T, et al: Vitamin K2 covalently binds to Bak and induces Bak-mediated apoptosis. Mol Pharmacol 83: 613-620, 2013.

62. Dranka BP, Hill BG and Darley-Usmar VM: Mitochondrial reserve capacity in endothelial cells: the impact of nitric oxide and reactive oxygen species. Free Radic Biol Med 48: 905-914, 2010.

63. Benz CC, Atsriku C, Yau C, et al: Novel pathways associated with quinone-induced stress in breast cancer cells. Drug Metab Rev 38: 601-613, 2006

64. Bolton JL, Trush MA, Penning TM, Dryhurst G and Monks TJ: Role of quinones in toxicology. Chem Res Toxicol 13: 135-160, 2000.

65. Lamson DW, Gu YH, Plaza SM, Brignall MS, Brinton CA and Sadlon AE: The vitamin C: vitamin K3 system - enhancers and inhibitors of the anticancer effect. Altern Med Rev 15: 345-351, 2010.

66. Ambs S and Glynn SA: Candidate pathways linking inducible nitric oxide synthase to a basal-like transcription pattern and tumor progression in human breast cancer. Cell Cycle 10: 619-624, 2011.

67. Lee J, Giordano S and Zhang J: Autophagy, mitochondria and oxidative stress: cross-talk and redox signalling. Biochem J 441: 523-540, 2012

68. Doulias PT, Tenopoulou M, Greene JL, Raju K and Ischiropoulos H: Nitric oxide regulates mitochondrial fatty acid metabolism through reversible protein S-nitrosylation. Sci Signal 6: rs1, 2013.

69. Lusini L, Tripodi SA, Rossi R, et al: Altered glutathione antioxidant metabolism during tumor progression in human renal-cell carcinoma. Int J Cancer 91: 55-59,2001.

70. Fitzgerald JP, Nayak B, Shanmugasundaram K, et al: Nox4 mediates renal cell carcinoma cell invasion through hypoxiainduced interleukin 6- and 8- production. PLoS One 7: e30712, 2012.

71. Abdelmohsen $\mathrm{K}$ : Epidermal growth factor receptor is a common mediator of quinone-induced signaling leading to phosphorylation of connexin-43: Role of glutathione and tyrosine phosphatases J Biol Chem 278: 38360-38367, 2003.

72. Suhara Y, Hanada N, Okitsu T, et al: Structure-activity relationship of novel menaquinone-4 analogues: modification of the side chain affects their biological activities. J Med Chem 55: 1553-1558, 2012.

73. Suhara Y, Watanabe M, Motoyoshi S, et al: Synthesis of new vitamin $\mathrm{K}$ analogues as steroid and xenobiotic receptor (SXR) agonists: insights into the biological role of the side chain part of vitamin K. J Med Chem 54: 4918-4922, 2011.

74. Mazurek S: Pyruvate kinase type M2: a key regulator of the metabolic budget system in tumor cells. Int J Biochem Cell Biol 43: 969-980, 2011.

75. Wong N, De Melo J and Tang D: PKM2, a central point of regulation in cancer metabolism. Int J Cell Biol 2013: 242513, 2013.

76. Chen J, Jiang Z, Wang B, Wang Y and Hu X: Vitamin K(3) and $\mathrm{K}(5)$ are inhibitors of tumor pyruvate kinase M2. Cancer Lett 316 204-210, 2012.

77. Anastasiou D, Poulogiannis G, Asara JM, et al: Inhibition of pyruvate kinase $\mathrm{M} 2$ by reactive oxygen species contributes to cellular antioxidant responses. Science 334: 1278-1283, 2011.

78. Zaunmuller T, Kelly DJ, Glockner FO and Unden G: Succinate dehydrogenase functioning by a reverse redox loop mechanism and fumarate reductase in sulphate-reducing bacteria. Microbiology 152: 2443-2453, 2006.
79. Sakai C, Tomitsuka E, Esumi H, Harada S and Kita K: Mitochondrial fumarate reductase as a target of chemotherapy: from parasites to cancer cells. Biochim Biophys Acta 1820: 643-651, 2012.

80. Tomitsuka E, Kita K and Esumi H: The NADH-fumarate reductase system, a novel mitochondrial energy metabolism, is a new target for anticancer therapy in tumor microenvironments. Ann NY Acad Sci 1201: 44-49, 2010.

81. Tomitsuka E, Kita K and Esumi H: An anticancer agent, pyrvinium pamoate inhibits the NADH-fumarate reductase system - a unique mitochondrial energy metabolism in tumour microenvironments. J Biochem 152: 171-183, 2012.

82. Tomlinson IP, Alam NA, Rowan AJ, et al: Germline mutations in FH predispose to dominantly inherited uterine fibroids, skin leiomyomata and papillary renal cell cancer. Nat Genet 30: 406-410, 2002.

83. Yang Y, Valera V, Sourbier C, et al: A novel fumarate hydratasedeficient HLRCC kidney cancer cell line, UOK268: a model of the Warburg effect in cancer. Cancer Genet 205: 377-390, 2012.

84. Ternette N, Yang M, Laroyia M, et al: Inhibition of mitochondrial aconitase by succination in fumarate hydratase deficiency. Cell Rep 3: 689-700, 2013.

85. Barrios-Rodiles M,Brown KR,Ozdamar B, et al: High-throughput mapping of a dynamic signaling network in mammalian cells. Science 307: 1621-1625, 2005.

86. Behrends C, Sowa ME, Gygi SP and Harper JW: Network organization of the human autophagy system. Nature 466: 68-76, 2010.

87. Perez Jurado LA, Wang YK, Francke U and Cruces J: TBL2, a novel transducin family member in the WBS deletion: characterization of the complete sequence, genomic structure, transcriptional variants and the mouse ortholog. Cytogenet Cell Genet 86: 277-284, 1999.

88. Tieu Q and Nunnari J: Mdvlp is a WD repeat protein that interacts with the dynamin-related GTPase, Dnm1p, to trigger mitochondrial division. J Cell Biol 151: 353-366, 2000.

89. Tieu Q, Okreglak V, Naylor K and Nunnari J: The WD repeat protein, Mdvlp, functions as a molecular adaptor by interacting with Dnm1p and Fis1p during mitochondrial fission. J Cell Biol 158: 445-452, 2002.

90. Feng Y, Zhang C, Luo Q, et al: A novel WD-repeat protein, WDR26, inhibits apoptosis of cardiomyocytes induced by oxidative stress. Free Radic Res 46: 777-784, 2012.

91. Blattmann P, Schuberth C, Pepperkok R and Runz H: RNAibased functional profiling of loci from blood lipid genome-wide association studies identifies genes with cholesterol-regulatory function. PLoS Genet 9: e1003338, 2013.

92. Rothblat GH, De la Llera-Moya M, Atger V, Kellner-Weibel G, Williams DL and Phillips MC: Cell cholesterol efflux: integration of old and new observations provides new insights. J Lipid Res 40: 781-796, 1999.

93. Hoekstra M, van Berkel TJ and van Eck M: Scavenger receptor BI: a multi-purpose player in cholesterol and steroid metabolism. World J Gastroenterol 16: 5916-5924, 2010.

94. Maitra U and Li L: Molecular mechanisms responsible for the reduced expression of cholesterol transporters from macrophages by low-dose endotoxin. Arterioscler Thromb Vasc Biol 33: 24-33, 2013.

95. Saddar S, Carriere V, Lee WR, et al: Scavenger receptor class B type I is a plasma membrane cholesterol sensor. Circ Res 112: 140-151,2013.

96. Crestani M, De Fabiani E, Caruso D, et al: LXR (liver X receptor) and HNF-4 (hepatocyte nuclear factor-4): key regulators in reverse cholesterol transport. Biochem Soc Trans 32: 92-96, 2004.

97. Tu K, Zheng X, Yin G, Zan X, Yao Y and Liu Q: Evaluation of Fbxw7 expression and its correlation with expression of SREBP-1 in a mouse model of NAFLD. Mol Med Rep 6: 525-530, 2012.

98. Kumadaki S, Karasawa T, Matsuzaka T, et al: Inhibition of ubiquitin ligase F-box and WD repeat domain-containing 7alpha (Fbw7alpha) causes hepatosteatosis through Kruppel-like factor 5 (KLF5)/peroxisome proliferator-activated receptor gamma2 (PPARgamma2) pathway but not SREBP-1c protein in mice. J Biol Chem 286: 40835-40846, 2011.

99. Ntambi JM, Miyazaki M and Dobrzyn A: Regulation of stearoylCoA desaturase expression. Lipids 39: 1061-1065, 2004.

100. Wang J, Ban MR, Zou GY, et al: Polygenic determinants of severe hypertriglyceridemia. Hum Mol Genet 17: 2894-2899, 2008.

101. Kathiresan S, Melander O, Guiducci C, et al: Six new loci associated with blood low-density lipoprotein cholesterol, highdensity lipoprotein cholesterol or triglycerides in humans. Nat Genet 40: 189-197, 2008 
102. Verma S, Tabb MM and Blumberg B: Activation of the steroid and xenobiotic receptor, $\mathrm{SXR}$, induces apoptosis in breast cancer cells. BMC Cancer 9: 3, 2009.

103. Pani G, Galeotti T and Chiarugi P: Metastasis: cancer cell's escape from oxidative stress. Cancer Metastasis Rev 29: 351-378, 2010.

104. Montero J, Morales A, Llacuna L, et al: Mitochondrial cholesterol contributes to chemotherapy resistance in hepatocellular carcinoma. Cancer Res 68: 5246-5256, 2008.

105. Garcia-Ruiz C, Mari M, Colell A, et al: Mitochondrial cholesterol in health and disease. Histol Histopathol 24: 117-132, 2009.

106. Bonuccelli G, Tsirigos A, Whitaker-Menezes D, et al: Ketones and lactate 'fuel' tumor growth and metastasis: evidence that epithelial cancer cells use oxidative mitochondrial metabolism. Cell Cycle 9: 3506-3514, 2010.
107. Bonuccelli G, Whitaker-Menezes D, Castello-Cros R, et al: The reverse Warburg effect: glycolysis inhibitors prevent the tumor promoting effects of caveolin-1 deficient cancer associated fibroblasts. Cell Cycle 9: 1960-1971, 2010.

108. Behrend L, Henderson G and Zwacka RM: Reactive oxygen species in oncogenic transformation. Biochem Soc Trans 31: 1441-1444, 2003.

109. Ralph SJ, Rodríguez-Enríquez S, Neuzil J, Saavedra E and Moreno-Sánchez R: The causes of cancer revisited: 'Mitochondrial malignancy' and ROS-induced oncogenic transformation - why mitochondria are targets for cancer therapy. Mol Aspects Med 31: 145-170, 2010.

110. Sone H, Akanuma H and Fukuda T: Oxygenomics in environmental stress. Redox Rep 15: 98-114, 2010. 